\title{
Blastability and Ore Grade Assessment from Drill Monitoring for Open Pit Applications
}

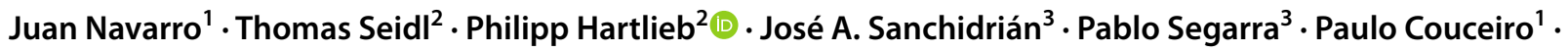 \\ Peter Schimek ${ }^{4} \cdot$ Clara Godoy $^{1}$
}

Received: 30 April 2020 / Accepted: 26 December 2020 / Published online: 17 April 2021

(c) The Author(s) 2021

\begin{abstract}
Blasting performance is influenced by mechanical and structural properties of the rock, on one side, and blast design parameters on the other. This paper describes a new methodology to assess rock mass quality from drill-monitoring data to guide blasting in open pit operations. Principal component analysis has been used to combine measurement while drilling (MWD) information from two drill rigs; corrections of the MWD parameters to minimize external influences other than the rock mass have been applied. First, a Structural factor has been developed to classify the rock condition in three classes (massive, fractured and heavily fractured). From it, a structural block model has been developed to simplify the recognition of rock classes. Video recording of the inner wall of 256 blastholes has been used to calibrate the results obtained. Secondly, a combined strength-grade factor has been obtained based on the analysis of the rock type description and strength properties from geology reports, assaying of drilling chips (ore/waste identification) and 3D unmanned aerial vehicle reconstructions of the post-blast bench face. Data from 302 blastholes, comprised of 26 blasts, have been used for this analysis. From the results, four categories have been identified: soft-waste, hard-waste, transition zone and hard-ore. The model determines zones of soft and hard waste rock (schisted sandstone and limestone, respectively), and hard ore zones (siderite rock type). Finally, the structural block model has been combined with the strength-grade factor in an overall rock factor. This factor, exclusively obtained from drill monitoring data, can provide an automatic assessment of rock structure, strength, and waste/ ore identification.
\end{abstract}

Keywords Measurement while drilling (MWD) · Ore grade recognition · Rock structural factor · Assaying · Automatic rock classification $\cdot$ Open pit $\cdot$ Blasting $\cdot$ Block model

\section{Introduction}

Mining consists of several unit operations linked to each other, and the performance of the initial stages (drilling, charging and blasting) pre-conditions the downstream unit operations in the production cycle (Ghosh 2017). For an efficient blasting, it is essential to have a well-defined

Philipp Hartlieb

philipp.hartlieb@unileoben.ac.at

1 MAXAM, Avenida del Partenón 16, 28042 Madrid, Spain

2 Montanuniveristaet Leoben, Franz Josef-Straße 18, 8700 Leoben, Austria

3 Universidad Politécnica de Madrid-E.T.S.I. Minas y Energía, Ríos Rosas, 21, 28003 Madrid, Spain

4 VA Erzberg GmbH, Erzberg 1, 8790 Eisenerz, Austria characterization of the rock mass; automatization in mining allows obtaining large amounts of data that bring new possibilities of optimization.

Rock mass is a combination of materials with different mechanical properties, intersected by discontinuities. Rock mechanical properties normally refer to strength (uniaxial compressive strength, UCS), deformation (Young's modulus and Poisson's ratio, assuming that the rock mass is an isotropic linear elastic body) and stability characteristics (cohesion and friction angle) (Zhao et al. 2018; Aydan et al. 2014). These features are normally obtained by laboratory experiments of core samples from intact rock or by in situ tests and describe the general mechanical characteristics of the rock type/s that compose the deposit. On the other hand, the structural condition of the rock mass is characterized by the degree of jointing (i.e. density and orientation of discontinuities), and discontinuity characteristics (i.e. roughness, 
alteration, composition, among others) (Palmström et al. 2001). These properties are evaluated with indexes such as Geological Strength Index (GSI, Hoek 1994), Rock Quality Designation (RQD, Deere and Miller 1966), Rock Mass Rating (RMR, Bieniawski 1995) and/or Q-Barton (Barton et al. 1974).

The in-situ structural condition modifies the strength of the intact rock; the existence of cavities, discontinuities, or fractured zones changes the response of the rock mass upon blasting. In blasting, rock density, uniaxial compressive strength, Young Modulus, orientation of discontinuities with respect to the free face of the blast and the spacing between them have been consistently employed to rate the blastability of the rock, starting with Lilly $(1986,1992)$. Lilly's blastability index has been used to predict the median size through the modified Kuznetsov equation in the KuzRam model (Kuznetsov 1973; Cunningham 1987, 2005), and has also been used recently to describe rock mass characteristics by Sanchidrián and Ouchterlony (2017) in the xp-fragmentation distribution-free model. A detailed rock mass characterization, based upon the combination of both mechanical, structural and chemical properties, is thus one of the most important requirements to control the ore to be mined and to improve blasting results by adapting the explosive energy distribution to the rock condition so as to optimize the performance of downstream stages such as digging, hauling and comminution.

Mine planning and design are often based on rock mass properties (Deere and Miller 1966; Barton et al. 1974; Bieniawski 1995), that are normally characterized by costly drill cores. To reduce costs, few widely spaced holes are usually logged and the ground conditions between them are interpolated (Schunnesson 1997). This often leads to a largescale characterization of the rock mass, and to an inaccurate knowledge of the mechanical and structural rock mass properties at a small scale (e.g. a bench or a block to be blasted). This significantly impacts the results of the operation and may increase production costs, reducing the efficiency of the fragmentation and thus the efficiency of digging and comminution stages, and eventually the safety if rock conditions are inadvertently poor. Since rock characteristics have an important influence on the drilling response (Hatherly et al. 2015; Peng et al. 2005; Schunnesson et al. 2011), technologies based on monitoring the performance of drill rigs by measuring drill parameters should be able to assess changes in the rock mass with high resolution (Navarro 2019).

Measurement while drilling (MWD) is a technique that logs drilling data at predetermined length intervals, providing information on the operational parameters involved in the drilling (Schunnesson 1997). This technology, able to provide high-resolution data with minimal disturbance in the production, has made MWD a complementary tool for rock mass characterization and geotechnical ground recognition. However, despite the advantages of this technology, the massive data recorded per blast and the difficulties of interpretation complicate its application as a decision-making tool in the daily routine of construction and mining works.

Substantial research efforts aimed to correlate the MWD technology with the geological/mechanical interpretation of the rock mass, on one side, and with the structural condition, on the other, have been reported. Related to the geological interpretation, for rotary drilling, Scoble et al. (1989) defined different geological formations from the analysis of variations in the logged parameters. For the mechanical rock characterization, for rotary drilling, Peck (1989) found a correlation between the monitoring parameters, the rock compressive strength and the shear strength; Teale (1965) and Liu and Karen (2001) studied the concept of specific energy, from drilling parameters, as the energy required to excavate a unit volume of rock; Leung and Scheding (2015) developed a coal-seam detection model called Modulated Specific Energy. For rotary-percussive drilling, among others, Schunnesson et al. (2012) described a methodology to assess rock strength ranges based on the MWD hardness index provided by Atlas Copco software; Kahraman et al. (2016) studied correlations between penetration rate, UCS, Brazilian tensile strength, point load strength and Schmidt hammer tests.

About MWD interpretation on the structural rock condition, for rotary-percussive drilling, Schunnesson (1997) proposed a methodology to estimate the RQD index based on the penetration rate and torque pressure, and their variation, that shows a close correlation with the presence of discontinuities; Peng et al. (2005) and Tang (2006) developed a method to measure void/fractures in tunnel roofs from bolt drilling; van Eldert et al. (2020) correlated the MWD data to the RQD index and suggested an approach on the use of this technology for rock support design to improve cost efficiency in tunneling projects. For Wassara water-hydraulic ITH (in-the-hole) drilling, Ghosh et al. (2018) and Navarro et al. (2019) developed a probabilistic geotechnical rock classification model for fan-shaped long-holes drilling in underground production operations.

On the other hand, Epiroc (2020), Sandvik (2020) and Bever Control (2020), in collaboration with AMV (AMV 2019), have developed software for their own drilling equipment (Tunnel Manager MWD, iSURE and Bever Control, respectively) as a tool for management and assessment of drill parameters. From collected MWD files, 3D representations of hardness or fracturing indexes are provided independently.

None of the above methods or systems cover the combined analysis and representation of both mechanical and structural properties together. In addition, to the authors' 
knowledge, few of them have been applied to blast design and validated in production environments.

This paper develops a new methodology for a sound rock characterization based on two new indexes from MWD records: the first one classifies the structural condition of the rock from the variability of the MWD parameters and a discontinuity factor by using principal components analysis (PCA); the second represents a combination of the strength properties and iron content of the rock, based on the combination of MWD parameters. Before being used for the analysis, a thorough correction of the MWD parameters has been applied to minimize external influences other than the rock mass.

The analysis is applied to data from the Erzberg Mine, a large iron open pit mine in Austria. The Structural factor classifies the rock condition in three classes: massive, fractured and heavily fractured. This classification has been validated and calibrated from video recordings of the inner wall of 207 blastholes. From it, a structural block model has been developed to simplify the automatic recognition of rock trends.

The strength-grade factor has been assessed from a combined analysis of the rock type description and UCS from geology reports, assays of the drill cuttings (ore/ waste identification) and 3D unmanned aerial vehicle (UAV) reconstructions of the post-blast bench face. The factor ranks the rock into four categories: soft-waste, hardwaste, transition zone and hard-ore. MWD signals from 302 holes in 26 blasts (see Blast IDs B1-B26 in Table 2), assays of the drill cuttings for 207 of the 302 blastholes and geology reports of each blast, have been used for this analysis. The strength-grade factor has been validated for two blasts comparing the assays at intervals of $6 \mathrm{~m}$ with the strength-grade factor value associated with each interval.

Finally, the structural block model has been combined with the strength-grade Factor in an overall novel Rock Factor that, exclusively based on drill monitoring data, can provide a blast ability assessment based on the rock structure, strength and waste/ore identification.

\section{Data Overview}

\subsection{Test Site and Geology}

The Erzberg mine is the largest open-pit iron ore mine in middle Europe and the largest deposit of siderite in the world. It is located in the central-western part of Austria. The main iron mineral is a magnesium-rich variety of siderite with an iron content between 20 and $42 \%$. Other iron minerals are ankerites with differing iron content between 10 and $17 \%$. Beside ankerite, the main waste materials within the ore bearing formation are different types of limestone. The floor of the deposit is formed by a volcanic silicate rock and the overburden by a partly schisted sandstone. Table 1 lists the lithologies analyzed in the study along with the UCS value assigned from geological reports, and the ore/waste classification. A reference image of each rock type is also included.

\subsection{Drill System and Data Information}

The rock mass is excavated by bench blasting using one or two rows of inclined holes with a length of 15-30 m. Two SmartROC D65 DTH fully mechanized drill rigs manufactured by Epiroc are used for the drilling. Positioning of the holes is controlled by the operator but drilling and logging of drill parameters are done automatically. Drilling is done using extension tubes of $6 \mathrm{~m}$ length and a bit diameter of 6" $(152 \mathrm{~mm})$. A 4.16 revision control system was installed in the rigs and a sample interval of $0.05 \mathrm{~m}$ was set to monitor the information. This makes up to 460 sample points per blast hole considering an average blast hole length of $23 \mathrm{~m}$.

The drill parameters recorded while drilling are the following (acronyms and units for each parameter in brackets):

- Feed pressure (FP, bar): hydraulic pressure inside the feed cylinders that generates the force necessary to keep the bit in contact with the bottom of the hole during the impact of the piston.

Table 1 Rock type classification

\begin{tabular}{|c|c|c|c|}
\hline Rock Type & Schisted sandstone & Limestone & Siderite \\
\hline UCS (MPa) & 40 & 125 & 125 \\
\hline Ore/Waste & Waste & Waste & Ore \\
\hline Reference imag & & & \\
\hline
\end{tabular}


Table 2 Data information

\begin{tabular}{|c|c|c|c|c|c|c|c|}
\hline Blast ID & Drill rig & $\begin{array}{l}\text { No. of holes } \\
\text { drilled per blast }\end{array}$ & $\begin{array}{l}\text { MWD (no. } \\
\text { of holes) }\end{array}$ & $\begin{array}{l}\text { In-hole videos } \\
\text { (no. of holes) }\end{array}$ & $\begin{array}{l}\text { UAV (no. of } \\
\text { photos) }\end{array}$ & $\begin{array}{l}\text { Assays of drill cut- } \\
\text { tings (no. of holes) }\end{array}$ & rock type \\
\hline B1 & D1 & 16 & 13 & 14 & 115 & 16 & Lim and Sid \\
\hline B2 & D1 & 5 & 4 & 5 & 162 & 5 & Schist Sand \\
\hline B3 & D2 & 9 & 9 & 9 & 105 & 9 & Lim \\
\hline B4 & D1 & 11 & 9 & 11 & 126 & 11 & Lim and Sid \\
\hline B5 & D1 & 15 & 14 & 15 & 178 & - & Schist Sand and Sid \\
\hline B6 & D2 & 11 & 10 & 11 & 142 & - & Lim and Sid \\
\hline B7 & D1 & 19 & 17 & 16 & 227 & 19 & Lim and Sid \\
\hline B8 & D2 & 12 & 11 & 12 & 135 & 12 & Lim and Sid \\
\hline B9 & D1 & 9 & 8 & 9 & 224 & 9 & Lim and Sid \\
\hline B10 & D1 & 10 & 10 & 10 & 293 & 10 & Sid \\
\hline B11 & D1 & 16 & 16 & 15 & 208 & 16 & Sid \\
\hline B12 & D2 & 11 & 10 & 8 & 131 & 11 & Lim \\
\hline B13 & D1 & 11 & 11 & 9 & 204 & 11 & Sid \\
\hline B14 & D1 & 19 & 19 & 16 & 133 & - & Sid \\
\hline B15 & D1 & 12 & 11 & 12 & 231 & 12 & Lim \\
\hline B16 & D2 & 13 & 13 & 9 & 146 & 13 & Schist Sand, Lim and Sid \\
\hline B17 & D2 & 23 & 23 & 17 & 165 & - & Schist Sand and Lim \\
\hline B18 & D1 & 10 & 10 & 9 & 141 & 10 & Sid \\
\hline B19 & D2 & 15 & 14 & - & 149 & - & Lim and Sid \\
\hline B20 & D2 & 17 & 17 & - & 263 & - & Sid \\
\hline B21 & D1 & 12 & 11 & - & 187 & - & Lim and Sid \\
\hline B22 & D1 & 8 & 7 & - & 215 & - & Sid \\
\hline B23 & D1 & 12 & 10 & - & 235 & - & Sid \\
\hline B24 & D2 & 9 & 9 & - & 283 & - & Lim and Sid \\
\hline B25 & D2 & 10 & 10 & - & 129 & $4(18)^{\mathrm{a}}$ & Schist Sand, Lim and Sid \\
\hline B26 & D2 & 6 & 6 & - & 72 & $5(25)^{\mathrm{a}}$ & Schist Sand, Lim and Sid \\
\hline 26 & 15(D1)/11(D2) & 321 & 302 & 207 & 4599 & 207 & \\
\hline
\end{tabular}

Schist Sands. schisted sandstone, Lim. Limestone, Sid. siderite

${ }^{a}$ Assaying carried out at intervals of $6 \mathrm{~m}$ length; this comprises 18 analyses for B25 and 25 for B26

- Percussive pressure (PP, bar): impact pressure acting on the piston in the rock drill.

- Rotation pressure (RP, bar): pressure to generate the torque on the drill rod to maintain the required rotation speed of the bit.

- Penetration rate (PR, $\mathrm{m} / \mathrm{min})$ : speed at which the drill bit advances through the rock mass.

- Air pressure (AP, bar): pressure of the air used to flush out the drill cuttings from the blast hole. For the case under study, measurements of this parameter were not available for any of the two rigs.

- Hole depth (HD, m): length of the drilling at the sample point.

Table 2 describes the available data per blast for MWD, borehole videos, UAV flights, assaying, and the rock type/s identified from the geological reports.
In-borehole video recording was carried out by a digital camera manufactured by Kummert, composed by a front lens, illuminated by led lights. A protective steel frame was added to the front of the camera to prevent a possible collision between the rock and the glass of the camera. The data acquisition system was connected to the camera by an insulated cable. This was rolled in a cable wheel with a distance counter, so the image in the video is always linked to a depth. Video recordings of the borehole wall in front of the probe were done while lowering it. The extensive hole video recording program conducted in field tests allows to identify different structural rock conditions (represented in Fig. 1), such as areas of intact or massive (Fig. 1a), weakness (Fig. 1d) and heavily broken (Fig. 1g) rock; small isolated (Fig. 1b), medium-size (Fig. 1f) and large-size (Fig. 1d) fractures or discontinuities (open or filled); lithology changes (Fig. 1c); and small (Fig. 1f) and 


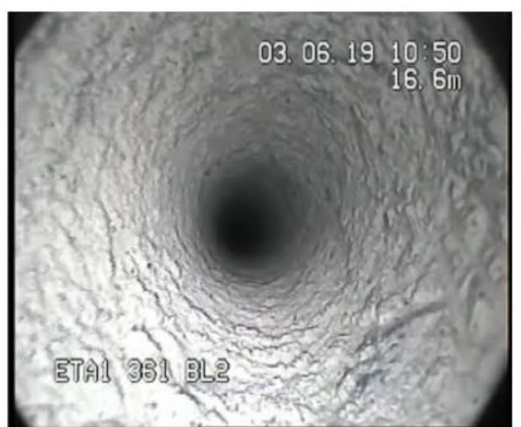

(a) Massive area

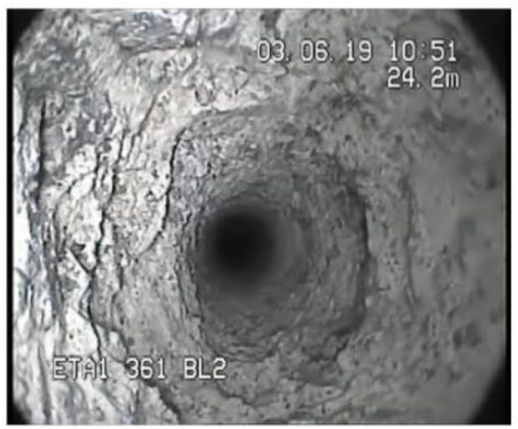

(d) Weakness area

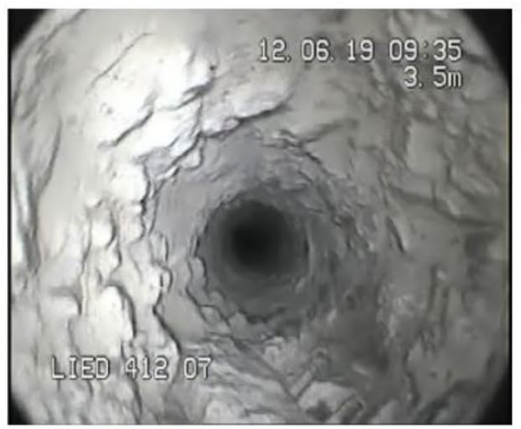

(g) Heavily broken area

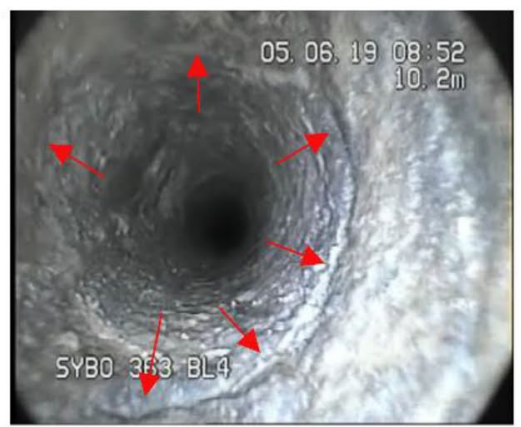

(b) Small-isolated discontinuity

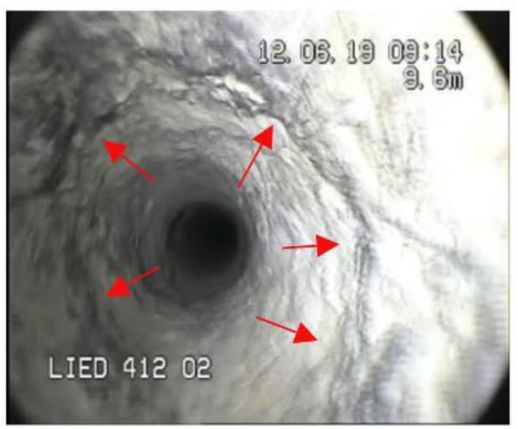

(e) Medium-size discontinuity

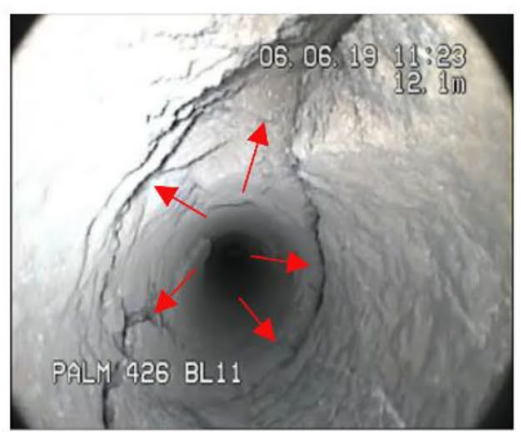

(h) Large-size discontinuity

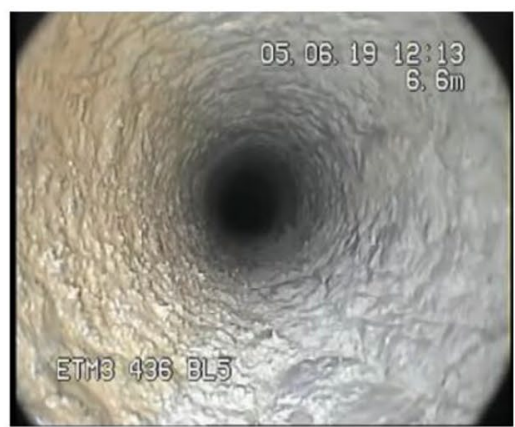

(c) Lithology change

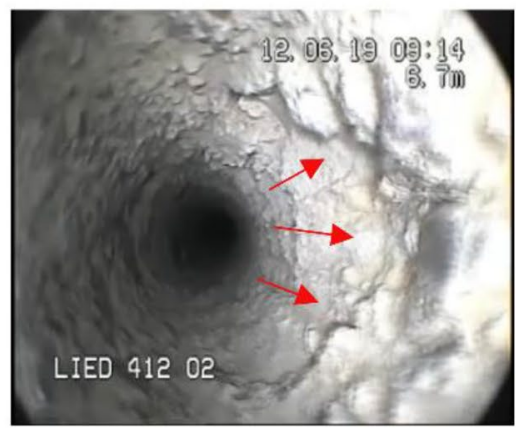

(f) Small Cavity

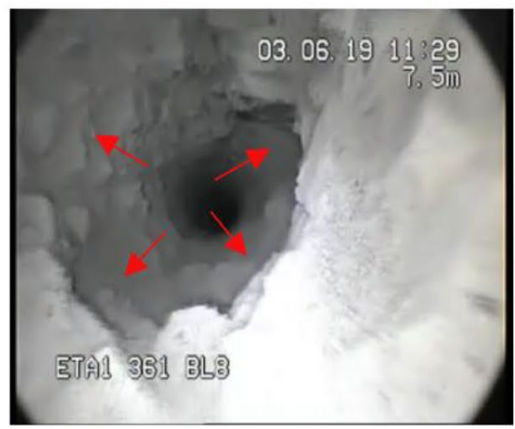

(i) Large Cavity

Fig. 1 Structural conditions identification from borehole video record

large (Fig. 1i) voids/cavities. Normally, a weakness area (Fig. 1d) is a combination of several small/medium size discontinues and/or small cavities. It may also be related to lithology intrusions of softer rock. A heavily broken area (Fig. 1g) is a low competent zone that includes a combination of medium/large size discontinues and/or medium/ large cavities.

UAV images correspond to the post-blast bench face after removing the muck-pile material. This face of the bench is closer to the blastholes so it can give a more accurate representation of the rock drilled. Photos were taken from a DJI Matrice 200 drone. Image processing has been done through Pix4D (2020) software providing georeferenced point clouds with RGB color information assigned to each point, as from the UAV images. Post-processing of the point cloud and 3D representation has been done with Matlab (2017).

Assaying is done over drill cuts gathered automatically while drilling. For that, cuttings are flushed out of the borehole with compressed air and transported away with a suction device. The collar of the blast hole is closed with a suction hood and the discharged cuttings are introduced in a cyclone. Samples are cyclically collected from the cyclone at a preset depth interval to cover the entire blast hole length. A sample mass of approximately $1-2 \mathrm{~kg}$ is collected in a container sealed to the ejection point of the cyclone. For blasts B1-B24, a container with samples of the entire blasthole length was collected per hole and sent to the lab for assaying. $\mathrm{X}$-ray Fluorescence Spectrometry was used to identify the 
different components of the sample materials. This determines an average measurement per hole of $\mathrm{Fe}$ content and other components such as $\mathrm{SiO}_{2}, \mathrm{CaO}, \mathrm{Al}_{2} \mathrm{O}_{3}, \mathrm{MgO}, \mathrm{Mn}$, $\mathrm{Na}_{2} \mathrm{O}, \mathrm{K}_{2} \mathrm{O}, \mathrm{S}$ and $\mathrm{P}$. In general, a rock with Fe content above $20 \%$ is considered ore and below waste. Special assaying was carried out for blasts B25 and B26, where sampling was performed at $6 \mathrm{~m}$ intervals along the hole so that several assays info was available along the holes.

\section{Data Analysis}

\subsection{MWD Data Processing}

One general problem with MWD data analysis is that the logged response is affected by the rock mass conditions, the drill rig control system and external influences different than the rock such as the calibration of the monitoring sensors, the hole length and/or the drill rig performance (Schunnesson 1998). All together adds uncertainty to the data that must be corrected to highlight changes in the parameters that depend on the rock properties. This process comprises: (1) filtering of unrealistic values, (2) removing of systematic peaks due to the addition of a new rod, and (3) correction of the hole depth influence.

\subsubsection{Filtering of Unrealistic Values}

Production data often includes unrealistic high and lowperformance values of the drill rig that may lead to a wrong interpretation of the MWD data. In line with the analysis followed by Navarro et al. (2018, 2019), the empirical probability distribution of each MWD parameter is built from the complete data set values (26 blasts, comprising
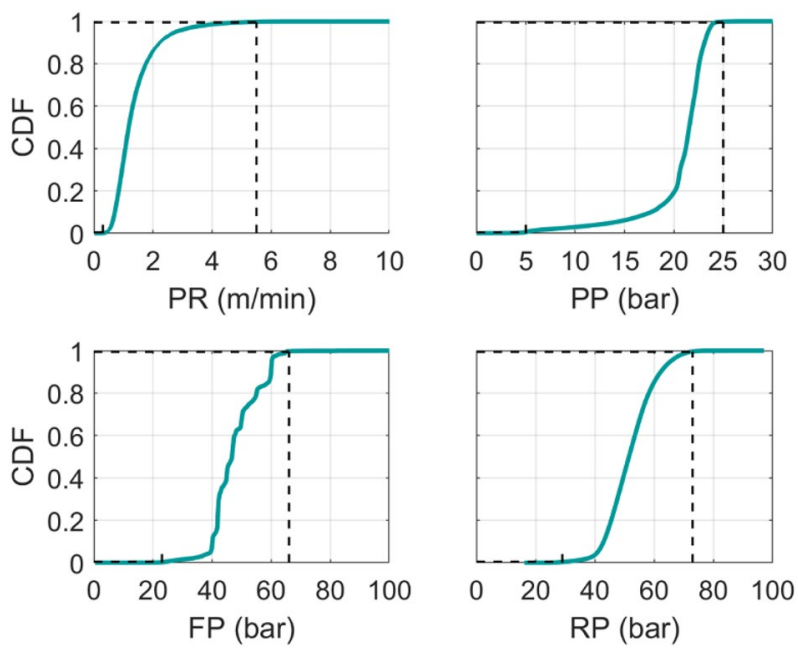

Fig. 2 Cumulative distribution function of the MWD parameters
302 blastholes sampled every $5 \mathrm{~cm}$, see Table 2). Values within the $99 \%$ confidence interval are retained for the analysis. Figure 2 shows the cumulative distribution functions (CDF) of four drilling parameters (data for DP and AP not available), where the black dashed horizontal lines mark the $99 \%$ coverage and the vertical lines mark the corresponding limits of the parameters, given in Table 3.

\subsubsection{Removing of Systematic Drops Due to the Addition of a New Rod}

For long holes, systematic variations are related to the parameters response when a new rod is added; when the drill reaches the end of the feeder, a new rod must be added to continue the drilling. During this procedure, percussive pressure, feed pressure and rotation pressure parameters are shut down, the drill rod is pulled back and the new rod is added to the end of the last one (Navarro et al. 2019). The logging system starts recording values again when the bit exceeds the last length measured. As an example, Fig. 3a represents the raw signal of the feed pressure for a single hole, where systematic drops at every $6 \mathrm{~m}$ can be seen, matching with the addition of a new rod. Such systematic variations, that do not reflect any information of the rock conditions, are automatically filtered out in a post-analysis routine coded in Matlab. Figure 3b shows the filtered signal from Fig. 3a, in which all peaks associated with rod changes have been removed. Noted that the peak at about $3 \mathrm{~m}$ is not removed by this filtering, since it does not correspond to rod additions, but to a possible rock disturbance.

\subsubsection{Correction of Hole Depth Influence}

Systematic variations generated by the drilling system and external influences other than the rock can be recognized and removed by averaging, for a large amount of data, the logged response (Schunnesson 1998). Procedures to normalize parameters to reduce external influences in the rig response have been described by Schunnesson (1998) for percussive drilling, Ghosh et al. (2018) and Navarro et al. (2019) for Wassara water-hydraulic ITH (in-the-hole) drilling in underground production operations, and Hjelme

Table 3 Range of reasonable values of MWD as from their 99\% confidence intervals

\begin{tabular}{lll}
\hline Parameter & Units & Thresholds \\
\hline Penetration rate (PR) & $\mathrm{m} / \mathrm{min}$ & $0.3<\mathrm{PR} \leq 5.5$ \\
Percussive pressure (PP) & bar & $5<\mathrm{PP} \leq 25$ \\
Feed pressure (FP) & bar & $22<\mathrm{FP} \leq 66$ \\
Rotation pressure (RP) & bar & $27<\mathrm{RP} \leq 73$ \\
\hline
\end{tabular}


(2010) and Navarro et al. (2018) for rotary-percussive drilling in tunneling works. However, no such analysis has been published for open pit operations.

Normally, variations with depth are partly related to the increasing energy losses when holes are longer, due to the reduction of the stress wave energy transmitted along the drill rod. It can also be related to the decreasing flushing efficiency with depth and the bit wear. Increasing frictional resistance between the drill rod and the blasthole walls can also cause this phenomenon (Schunnesson 1998). Although all these external influences will have an impact in the overall drilling system performance, some of the MWD parameters will be more affected by specific influences due to their physical behavior: FP and PP will be normally affected (as from literature in upwards and/or horizontal drilling) by the reduction of the stress wave energy transmitted along the drill rod, and the AP by the decreasing flushing efficiency; the RP parameter will be influenced by the frictional resistance between the drill rod and the blasthole walls, that will rise with increases of the rod length, resulting in higher values of the parameter; the PR will be affected by previous influences and by the bit wear, reducing its performance.

Figure 4 shows the average signals of penetration rate (Av.PR), percussive pressure (Av.PP), feed pressure (Av.FP) and rotation pressure (Av.RP) calculated at every $0.5 \mathrm{~m}$ hole length for the 302 blastholes analyzed. The calculation is shown for the two drill rigs separately (represented with a different color: black for D1 and red for D2), to see whether there is any other systematic variation caused by the calibration or set-up of the rig sensors. From the four graphs, rotation pressure (Av.RP) shows a well-defined increase with hole depth (HD) for the two rigs. It is noticeable that significant jumps occur in the signal of this parameter after adding a new rod, at $6,12,18$ and $24 \mathrm{~m}$ (see dashed lines, bottom right graph, Fig. 4). This can be caused by energy loses in the couplings after installing a new rod or by the additional difficulty to rotate the rod as the weight increases down the hole. The normalization of the hole length influence in the rotation pressure parameter is calculated for each rig separately as there are two different trends with different ranges of values; this may be caused by an irregular set-up or miscalibration of the sensors or drilling control system. The correction of the hole length influence (to obtain a signal $\mathrm{RP}_{\mathrm{Norm}}$ ) is done by:

$\mathrm{RP}_{\text {Norm }}^{i}=\left[\mathrm{RP}^{i}-\mathrm{RP}_{\mathrm{fit}}^{i}\right]+\mathrm{RP}_{\mathrm{fit}}^{1} ; \quad$ with $i=1,2, \ldots, N$,

where $i$ indicates each measurement in a hole $\log , N$ being the number of these. $\mathrm{RP}_{\text {fit }}$ is a polynomial fit with hole depth of Av.RP(bottom right graph, Fig. 4). The determination coefficient of the fit $R^{2}$ is 0.95 and 0.96 for drill rigs D1 and $\mathrm{D} 2$, respectively. $\mathrm{RP}_{\mathrm{fit}}^{1}$ is the intercept of the fit, i.e. the value at depth zero.

Average signals of penetration rate (Av.PR), percussive pressure (Av.PP) and feed pressure (Av.FP) show no significant influence of the hole depth and they are not normalized. This can be explained by the downwards drilling direction so that energy loses in the coupling of a new rod may not have much effect in the response of these parameters due to gravity; this is usually not the case in the underground production and tunneling studies mentioned above, where drilling is done for upwards and horizontal holes. Like rotation pressure, the penetration rate, the percussive pressure and feed pressure show different ranges of values and trends for each rig.

\section{Structural Model}

\subsection{Structural Factor}

Schunnesson (1998) claimed that when discontinuities or changes in the geotechnical rock condition are found, penetration rate and rotation pressure parameters show significant fluctuations, resulting in a noisy signal. Schunnesson (1997) for rotary-percussive drilling and Ghosh et al. (2018) for Wassara ITH hammer, demonstrated an increase in the fluctuation of the penetration rate and rotation pressure when drilling through a fractured zone. These variations are
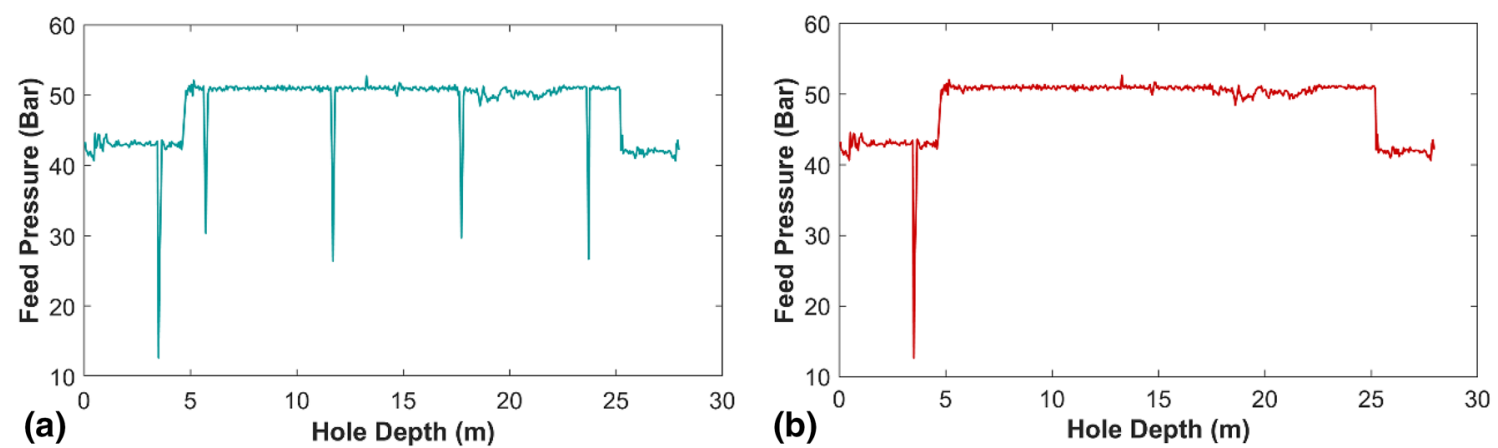

Fig. 3 Filtering of systematic peaks due to the addition of a new rod: a raw signal; $\mathbf{b}$ filtered signal 

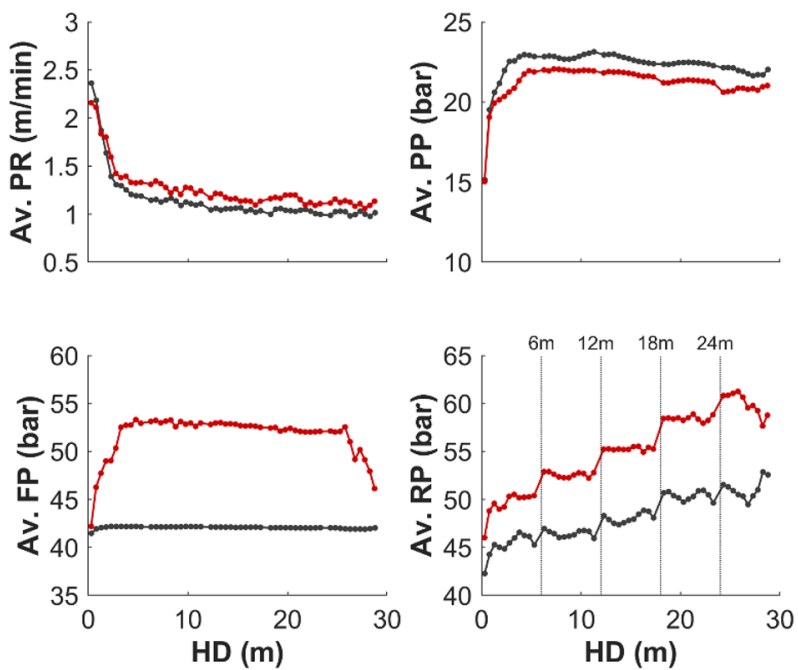

Fig. 4 Average signals for penetration rate (Av.PR), percussive pressure (Av.PP), feed pressure (Av.FP) and rotation pressure (Av.RP) with depth, calculated at every $0.5 \mathrm{~m}$ depth for the $302 \mathrm{MWD}$ data files. Black and red colors correspond to the average signals for drill rigs D1 and D2, respectively. HD is hole depth

highlighted and calculated as the sum of the residuals over a defined interval along the borehole:

$\mathrm{PR}_{\mathrm{var}, i}=\sum_{i}^{i+N}\left|\overline{\mathrm{PR}}_{i}-\mathrm{PR}_{i}\right|, \quad$ with $\quad i=1,2, \ldots, L-N$,

$\mathrm{RP}_{\mathrm{var}, i}=\sum_{i}^{i+N}\left|\overline{\mathrm{RP}_{i}}-\mathrm{RP}_{i}\right|, \quad$ with $\quad i=1,2, \ldots, L-N$,

where $\mathrm{PR}_{\mathrm{var}}$ is penetration rate variability, $\mathrm{RP}_{\mathrm{var}}$ is rotation pressure variability, $N$ is the window size and is considered $N=4$ (Ghosh 2017), $\overline{\mathrm{PR}}_{i}$ and $\overline{\mathrm{RP}}_{i}$ are the average values of the respective parameters within the window $N, i$ is the sample number, $L$ is the number of sample points of the MWD signal, and $\mathrm{PR}_{i}$ and $\mathrm{RP}_{i}$ are the penetration rate and rotation pressure, respectively, at each sample $i$.

The variability of both penetration rate and rotation pressure $\left(\mathrm{PR}_{\mathrm{var}}\right.$ and $\left.\mathrm{RP}_{\mathrm{var}}\right)$ at each sample $i$ have been combined in a discontinuity index (DI) using the local variability from Eqs. (2) and (3), each signal standardized with the mean and standard deviation:

$\mathrm{DI}_{i}=\sqrt{\frac{1}{2}\left(\frac{\mathrm{PR}_{\mathrm{var}, i}-\overline{\mathrm{PR}_{\mathrm{var}}}}{\mathrm{std}\left(\mathrm{PR}_{\mathrm{var}}\right)}\right)^{2}+\frac{1}{2}\left(\frac{\mathrm{RP}_{\mathrm{var}, i}-\overline{\mathrm{RP}_{\mathrm{var}}}}{\mathrm{std}\left(\mathrm{RP}_{\mathrm{var}}\right)}\right)^{2}}, \quad$ with $\quad i=1,2, \ldots, L$, where $\mathrm{PR}_{\mathrm{var}, i}$ and $\mathrm{RP}_{\mathrm{var}, i}$ are penetration rate variability and rotation pressure variability, respectively, at each sample number $i, L$ is the number of sample points of the $\mathrm{PR}_{\mathrm{var}}$ and $\mathrm{RP}_{\text {var }}$ signals and $\overline{\mathrm{PR}_{\mathrm{var}}}, \operatorname{std}\left(\mathrm{PR}_{\mathrm{var}}\right), \overline{\mathrm{RP}_{\mathrm{var}}}$ and $\operatorname{std}\left(\mathrm{RP}_{\mathrm{var}}\right)$ are average and standard deviation values of the penetration rate variability and rotation pressure variability.

Taking Ghosh et al. (2018) work as starting point, PCA have been used to correlate penetration rate, percussive pressure, feed pressure and normalized rotation pressure parameters, plus the calculated penetration rate variability, rotation pressure variability and the DI. The PCA is a method used to reduce the dimensionality of a multivariable dataset, while preserving as much 'variability' (i.e. statistical information) as possible, i.e., it finds new uncorrelated variables (named principal component) as linear functions or mixtures of those in the variables from the original dataset that maximize the variance between them and that squeeze or compress most of the information within the initial variables into the first components (Wold et al. 1987). The results of the PCA are normally represented in a two-dimensional biplot that shows, in form of a vector, the variables information contained in two of the principal components, where the direction and length of the vector indicate how each variable contributes to the two principal components in the plot. The two-dimensional biplot shows four quadrants: parameters closely represented in the same quadrant indicate potential positive correlations; on the contrary, parameters plotted in opposite quadrants are associated with negative correlation between them.

Since the purpose of this correlation is to identify local variations in the rock along the blasthole, the MWD parameters are standardized to minimize the effect of the different magnitudes in the parameters between drill rigs and the influence of the mechanical properties of the rock. Figure 5 represents the loading plot (influence of each parameter in the analysis) for the first and second principal components (PC1 and PC2, respectively). The plane generated by the two components explains the $66.02 \%$ (47.47\%, component 1 and $18.55 \%$, component 2 ) of the total variance. According to Fig. 5, the first component is dominated by the fracturing parameters $\left(\mathrm{PR}_{\mathrm{var}}, \mathrm{PR}_{\mathrm{var}}\right.$ and $\left.\mathrm{DI}\right)$ to the right and the percussive pressure and feed pressure to the left, showing a negative correlation between them. According to literature (Schunnesson 1998; Peng et al. 2005; Ghosh et al. 2018; Navarro et al. 2018) when there is a zone with discontinuities, fractures or open fissures, there is no resistance for the 
hammer to hit the rock and the impact pressure and, in consequence, the feed force is reduced to avoid damage in the system. In relation to the second component, the normalized rotation pressure dominates on the positive side.

The first component explains a larger variability in the data and the relation between parameters explains the drilling response to the rock. This does not happen in the second component in which all parameters are positive related; according to Ghosh (2017), the second component represents better the drill system influence. The first component is therefore used for the analysis.

Values obtained from PC1 have been visually compared with video records of the inner wall of the blastholes, aiming to associate the structural rock classes described in Fig. 1 to the different values of PC1. The analysis has been carried out for 17 of the 18 blasts, comprising 191 holes and more than 80,000 signal values. The remaining blast (B14) has been used as validation for the model. Based on the videos, three structural classes have been defined:

- Massive zone (MZ): zone composed by massive rock (Fig. 1a), small and/or isolated discontinuities and/or fractures filled with the rock of similar properties (Fig. 1b).

- Fractured zone (FZ): blocky zone composed by a weakness area (Fig. 1d), changes in the lithology by intrusions of softer material (Fig. 1c), medium-size discontinuities (Fig. 1e) and/or a small size cavity (Fig. 1f).

- Heavily Fractured zone (HFZ): zone of heavily broken rock mass (Fig. 1g), large size discontinuities (Fig. 1h) and/or medium or large cavities (Fig. 1i).

Significant variations and peaks in the fracturing index are always related to structural disturbances in the rock mass, the higher the value of the peak the more intense the disturbance. However, not all structural disturbances found in the videos generate a change in the drilling performance: horizontal or semi-horizontal small and isolated discontinuities which are thinner than the drilling sample interval (Fig. 1b), or fractures filled with a material of similar properties of rock have a minimum influence in drilling and they are included in the category of Massive zone. On the other hand, changes in the lithology by intrusions of softer material often create peaks and fluctuations in the signal, and they are included in the Fractured zone.

To rank the three structural classes in terms of the PC1, the probability distribution functions for each structural class are represented in Fig. 6. The point where two adjacent curves cross indicates the threshold between two structural zones.

Figure 7a and b represent, as an example, the Structural factor for two blastholes drilled in the validation blast (B14). Similar results are obtained for the rest of the blastholes of this blast. Images are located at the corresponding depths, with the definition of the specific structural class identified.

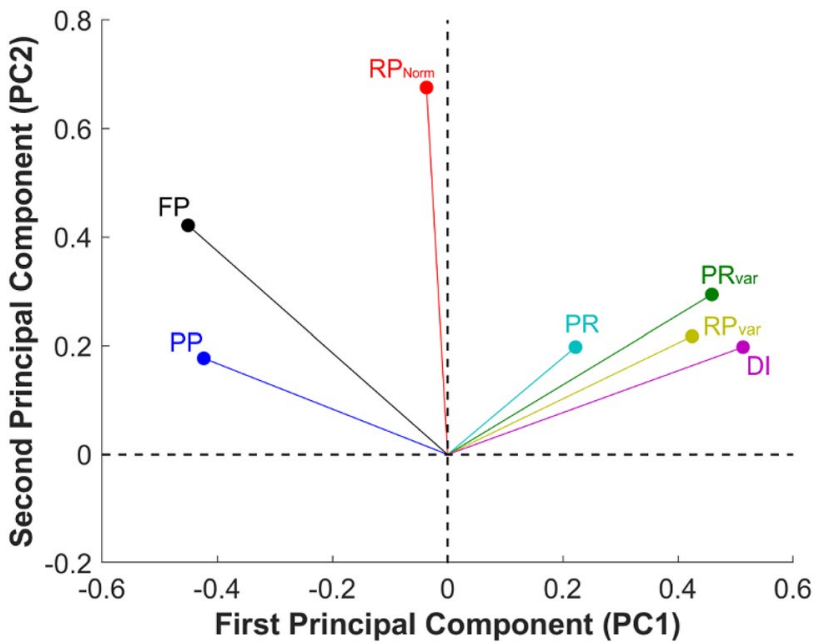

Fig. 5 Loading plot of PC1 And PC2 for the structural factor calculation: $\mathrm{PP}$ is percussive pressure, $\mathrm{FP}$ is feed pressure, $\mathrm{RP}_{\text {Norm }}$ is normalized rotation pressure, $\mathrm{PR}$ is penetration rate, $\mathrm{PR}_{\mathrm{var}}$ is penetration rate variability, $\mathrm{RP}_{\mathrm{var}}$ is rotation pressure variability and $\mathrm{DI}$ is discontinuity index

It is apparent that the Structural factor accurately identifies the different structural classes.

\subsection{Structural Block Model}

It is often difficult to interpret Structural factor graphs because of the existence of many small intervals of different rock classes, that complicates the automatic recognition of rock condition trends (Navarro et al. 2019). To solve this, the results of the Structural factor have been divided into zones based on abrupt changes of the mean value in the signal. Considering that the Structural factor is a signal $x$ of length $N$, the procedure divides the signal in $K$ sections and estimates the mean value and the residual error of the sections formed between them. Since $K$ is unknown, a penalty term $(\beta)$ is added to the residual error as a constant that grows linearly with the number of sections. The iteration finds $K$ such that the total residual error, $J(K)$, defined in Eq. (5), attains a minimum (Lavielle 1999, 2005; Killick et al. 2012).

$$
\begin{gathered}
J(K)=\sum_{j=0}^{K-1} \sum_{i=k_{j}}^{k_{j+1}-1}\left(x_{i}-\frac{1}{k_{j+1}-k_{j}} \sum_{r=k_{j}}^{k_{j+1}-1} x_{r}\right)^{2}+\beta K ; \\
k_{0}=1, \quad k_{K}=N+1 .
\end{gathered}
$$

To determine zones without losing important information in the signal related to structural rock features, $\beta$ is defined as $5 \%$ the maximum number of divisions of the signal at intervals of $0.3 \mathrm{~m}$. Figure 8 shows the result of this procedure for blasthole 3 (B14) represented in Fig. 7b; vertical black dashed lines indicate the edges of the sections and 


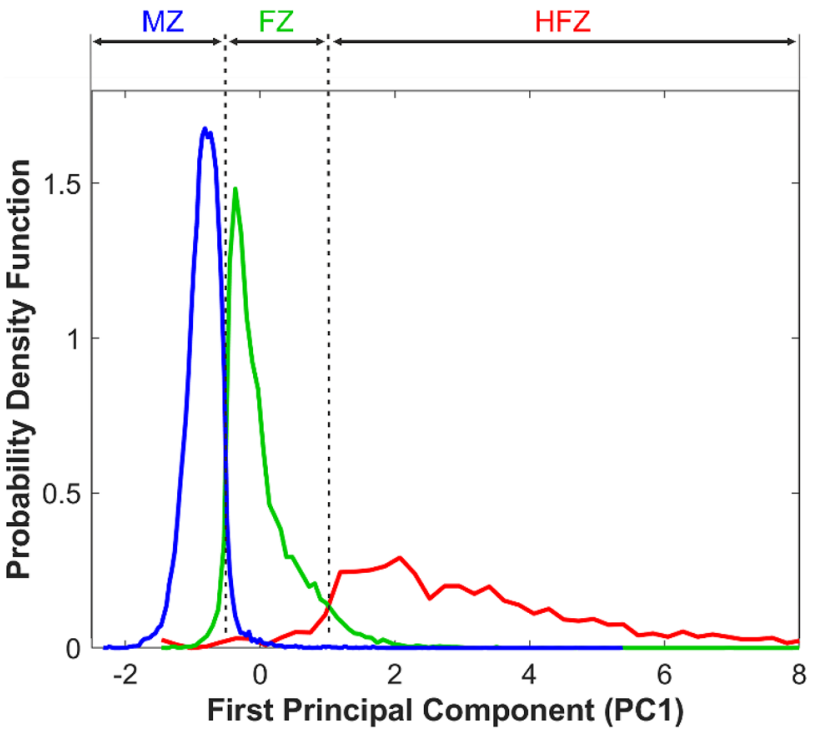

Fig. 6 Proposed Structural classes thresholds based on the probability density function of the Structural factor (PC1 values in Fig. 5) for each rock class. MZ is Massive zone, FZ is Fractured zone and HFZ is Heavily Fractured zone

thick horizontal lines represent the average values within these sections; they are colored according to their structural rock class (see legend). The analysis of the Structural factor is simpler now as minor fluctuations are filtered out.

The Structural Block Model can be applied to larger mine areas. The representation of the corresponding blastholes in a $3 \mathrm{D}$ plot is carried out by considering both collaring and end coordinates of the hole; the collar coordinates are given by the drill GPS positioning and the final point of the blasthole is estimated (assuming no deviations along its trajectory) using the azimuth and inclination angles of the drill arm and the preset blasthole length. This procedure is described in detail in Navarro et al. (2018, 2019).

Figure 9 shows the application of the structural block model for a production blast (B14) along with the 3D reconstruction of the post-blast bench face. The structural classes, massive, fractured and heavily fractured, are colored according to the legend. The first meters of the blastholes normally show a combination of fractured and heavily fractured zones, that may be related to damaged rock from upper blasts or the backfill material used to flatten out the ground. There are two areas of fractured zone trend marked with a yellow oval that coincides with a change of color in the rock and that may be related to a fractured area along this intersection. Other fractured and heavily fractured zones trends between adjacent blastholes (see magenta ovals) are also identified, related to areas of structural disturbances. The magenta circle to the left-bottom side of the bench shows the Heavily Fractured zone from blastholes 2 and 3 (Fig. 7) and how these disturbances are connected between them and with
Fractured zones of other adjacent holes. Finally, light-blue ovals show Fractured zones along individual blastholes that may indicate areas of nearly vertical discontinuities along the hole, not shown in the bench face.

\section{5 strength-grade factor}

The goal is to identify strength properties in the rock from the MWD data and to associate them with predominant lithologies (see Table 1) observed in the postblast face and the iron content (per hole) from assaying of the drilling chips (ore/waste identification). In line with Sect. 4, a PCA has been carried out on penetration rate, normalized rotation pressure, percussive pressure and feed pressure. Due to differences in the magnitude of the parameters between drill rigs (see Fig. 4), the PCA has been applied over the standardized MWD data. The analysis has been carried out for blasts B1-B24 (see Table 2), comprising 286 blastholes. The remaining blasts $\mathrm{B} 25$ and $\mathrm{B} 26$ have been used as validation of the model. Figure 10 represents the loading plot (influence of each parameter in the analysis) for PC1 and PC2. The plane generated by the two components explains $94.22 \%$ (88.61\%, component 1 and $5.61 \%$, component 2) of the total variation among all parameters. According to Fig. 10, the first component is highly dominated by the penetration rate on the positive side. This parameter is commonly used for hardness properties recognition (Schunnesson 1998), so its high influence is reasonable. Percussive pressure and feed pressure parameters dominate on the negative side, showing a negative correlation with the penetration rate. The feed pressure or thrust ensures that the bit keeps contact at the end of the hole to obtain a correct penetration rate; Schunnesson (1998) claimed that penetration rate tends to increase with an increase of thrust until a maximum penetration rate is reached, and further increases in the feed pressure make the penetration rate to decrease and sometimes to stall the drilling. On the other hand, sudden drops of the feed pressure due to fracture zones may cause a sharp increase of the penetration rate as a response to a high advance with no energy transfer to the rock. Excessive feed pressure in jointed rock causes rod jamming and in weak rock, the bit cannot break the rock effectively due to a deficient cuttings removal by the flushing system, which results in slow penetration (Pearse 1985; Schunnesson 1998). Similar to the PCA study of the structural model (Fig. 5), the normalized rotation pressure parameter dominates the second component on the positive side. Since component 1 covers nearly $90 \%$ of the total variation, it can be said that it carries most of the drill system's response to the geo-mechanical properties of the rock mass; thus, the following analysis is based on it. 


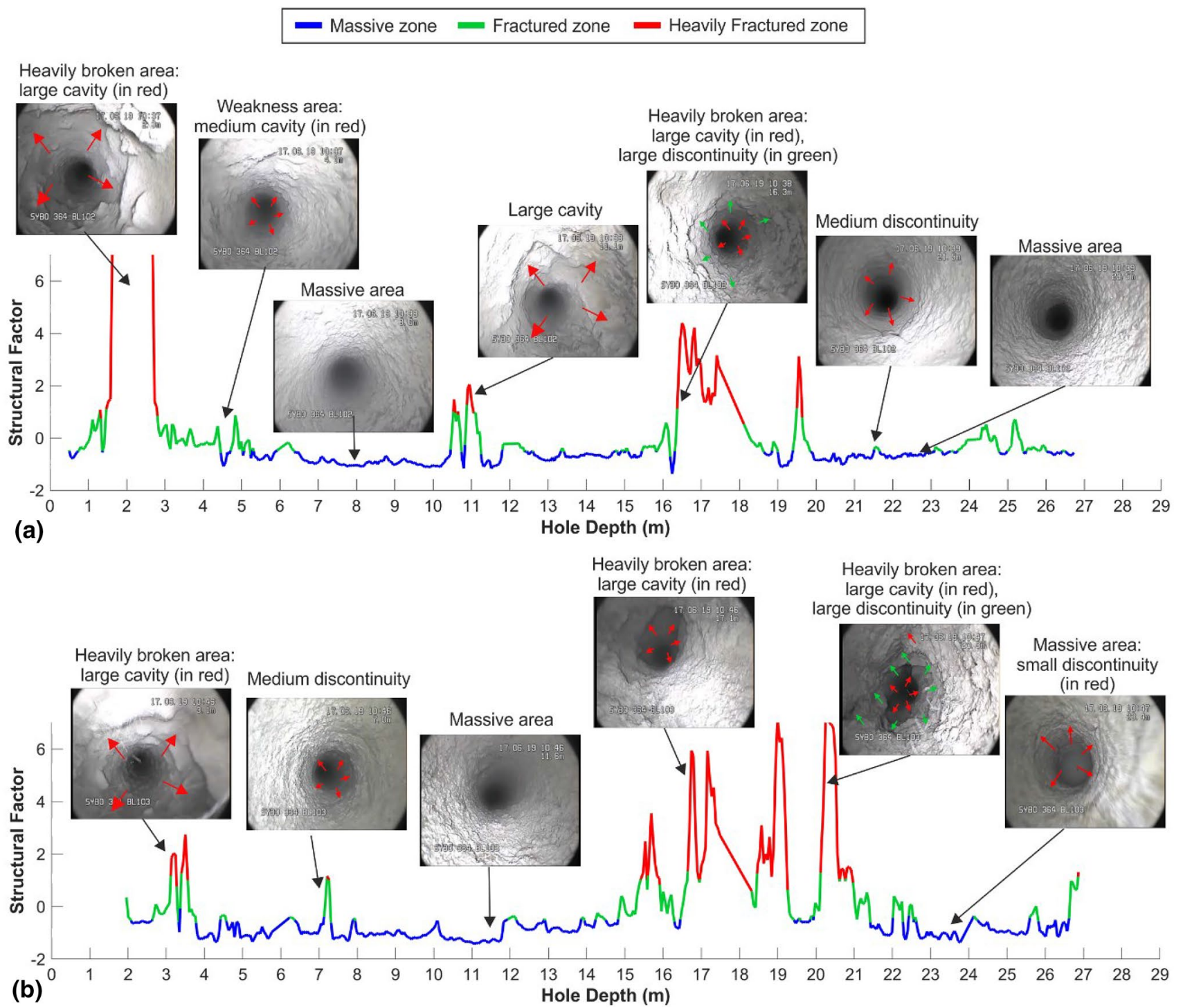

Fig. 7 Validation of the Structural factor from video records of the inner wall of two blastholes for Blast B14. a Row 1, hole 2; b row 1, hole 3

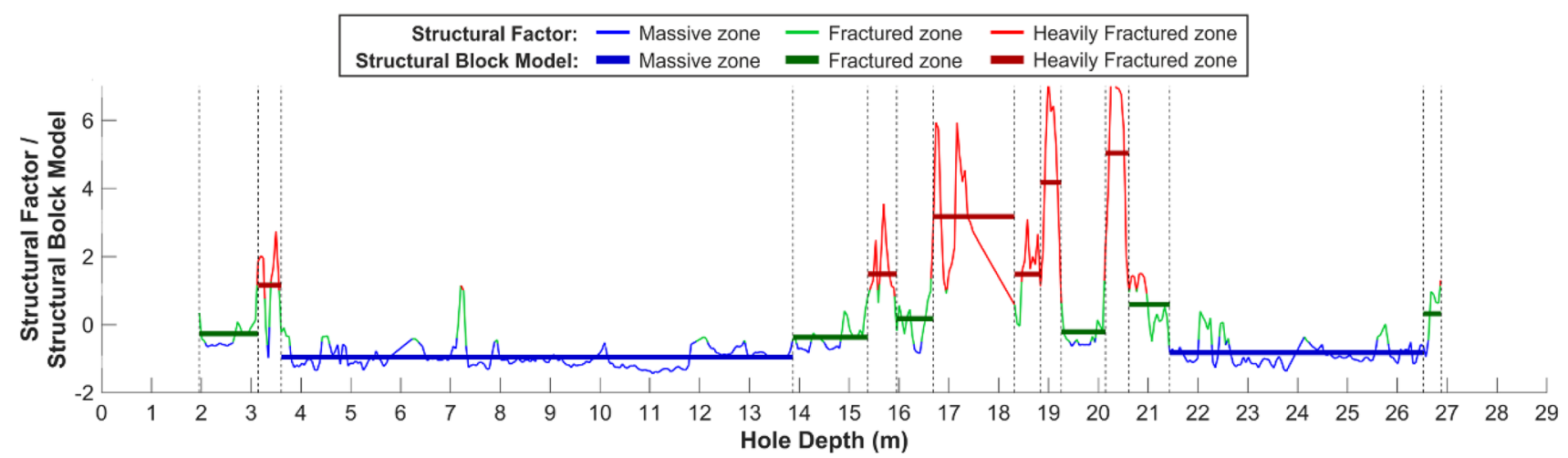

Fig. 8 Division of the structural factor in zones based on abrupt changes in mean value of the signal from blasthole 3 in blast B14 


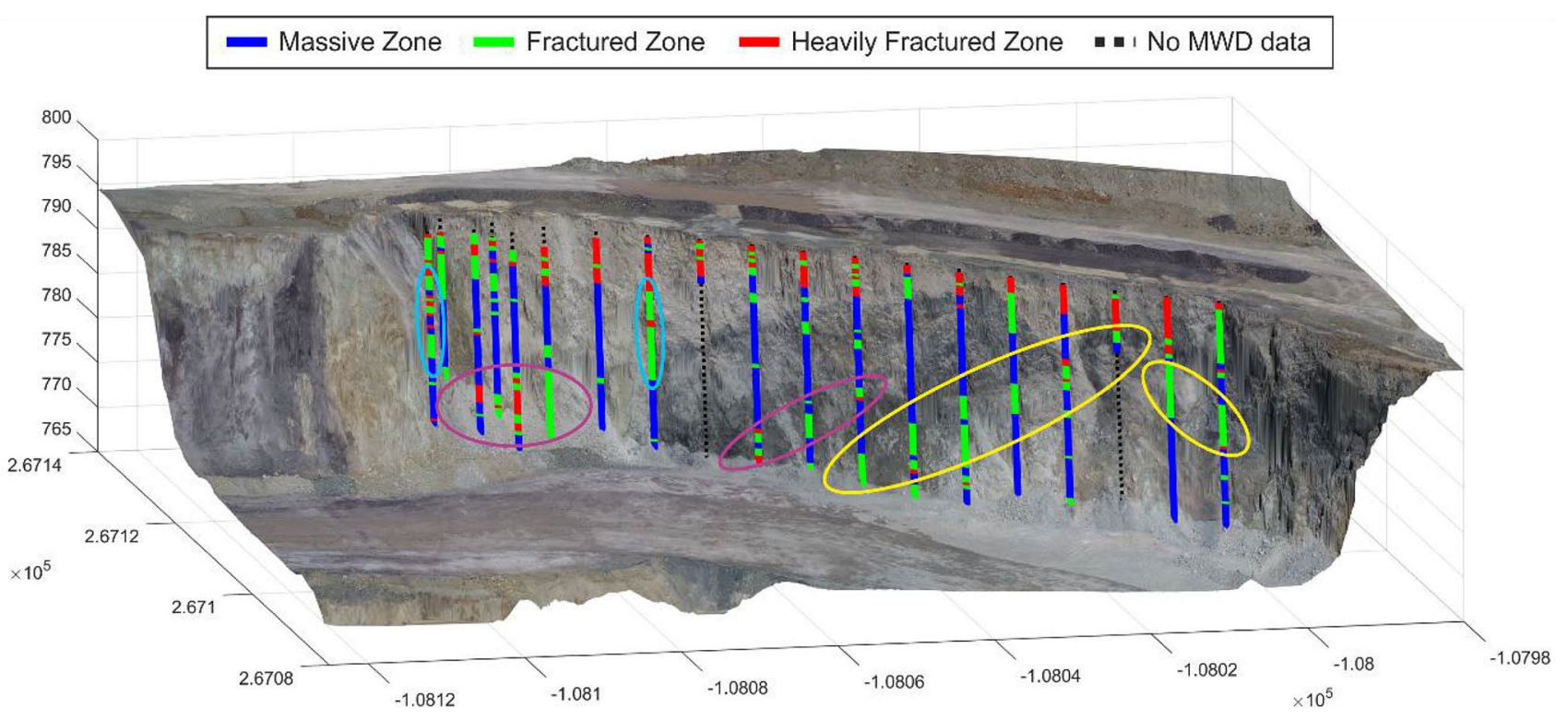

Fig. 9 Application of the structural block model for a production blast (B14) along with the 3D reconstruction of the post-blast bench face

Contrary to the structural block model, local variations in the signal are not relevant for the strength-grade analysis since they are normally caused by the local structural condition of the rock. The purpose here is to find dominant zones in the signal that may reflect strength trends from the MWD. For that, boreholes are divided in zones characterized by relatively constant mean values of the PC1, using Eq. (5) but, in this case, the penalty constant $\beta$ is defined as the maximum number of divisions of the signal at intervals of $1 \mathrm{~m}$. Figure 11 shows an example of the calculated zones for blastholes drilled in schisted sandstone (Fig. 11a), limestone (Fig. 11b) and siderite (Fig. 11c) rock types.

PC1 has been plotted against the iron content available for blasts B1-B24. Figure 12a represents, on one side, the correlation between the mean value of the longest section of $\mathrm{PC} 1$ and the chemical analysis (dots and diamonds markers, left axis); markers rare colored according to the lithology of the blast where the info was collected (as from geology reports, see Table 2). Data from rigs D1 and D2 are also differentiated (dots and diamonds, respectively). In general, values from both rigs are grouped together and follow the same trend, which indicates the consistency of the methodology used to standardize data from different drill rigs (see, Fig. 4). Figure 12a also shows the histograms PC1 classified into waste/ore according to the iron content (number of data in the histogram bars indicated in the right axis).

Rock areas associated with schisted sandstone and limestone rock types (magenta and gray markers, see Fig. 12a) are considered waste since their iron content is, in general, lower than the $20 \%$ (see Table 1). These markers are normally related to high PC1 values. As described in Table 1,

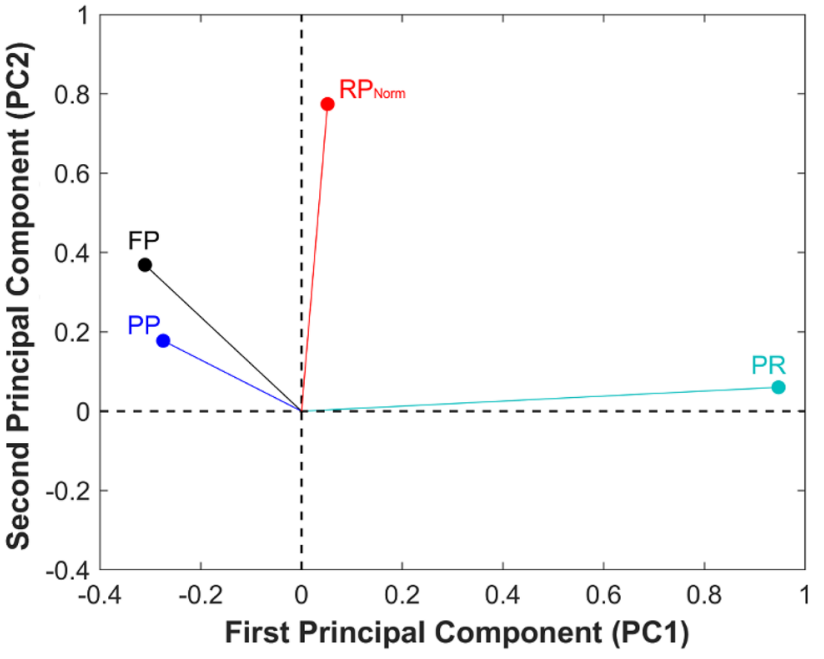

Fig. 10 Loading plot of PC1 and PC2 for the strength-grade factor calculation: PP is percussive pressure, FP is feed pressure, $\mathrm{RP}_{\text {Norm }}$ is normalized rotation pressure, $\mathrm{PR}$ is penetration rate

schisted sandstone and limestone have UCS values of $30 \mathrm{MPa}$ and $125 \mathrm{MPa}$, respectively. Since the PR parameter dominates the positive side of the PCA1 (see Fig. 10), and this is commonly used for hardness properties (the softer rock the higher its value), it is reasonable a higher PC1 for schisted sandstone than for limestone. On the other hand, blasts carried out in areas of siderite rock type (brown markers), which constitute the ore deposit with an iron content equal to or higher than $20 \%$, are associated to low PC1 values. Although limestone and siderite have a similar UCS 
value of around $125 \mathrm{MPa}$ (see Table 1), PC1 can differentiate the two rock types in most cases; for this reason, we have called PC1 a 'strength-grade' factor. However, there are situations where the drilling responds similarly to limestone and siderite, shown in the overlap zone of the histograms in Fig. 12a. Strength-grade factor values on the left side of the histogram for ore (light brown) and on the right side for waste (light gray) clearly represent potential identification of siderite and limestone lithologies, respectively. Values in the right tail of the waste histogram are associated with schisted sandstone.

From the results shown in Fig. 12a, four strength-grade categories of rock have been defined combining the rock type description and the iron content associated with the strength-grade factor values. These are indicated in Fig. 12a, separated by vertical dashed lines.

- Soft-waste: Strength-grade factor values associated to waste areas of schisted sandstone in $100 \%$ of the holes investigated.
- Hard-waste: Strength-grade factor values associated to waste areas of limestone in the $90 \%$ of the holes investigated.

- Transition zone: Strength-grade factor values related to a range of difficult recognition between limestone (waste) and siderite (ore). $39 \%$ of the holes falling into this category are drilled in waste and $61 \%$ in ore.

- Hard-ore: Strength-grade factor values associated with ore areas of siderite in $87 \%$ of the holes investigated.

The validation of the model has been carried out for blasts 25 and 26. For that, the strength-grade factor has been applied to the MWD data of these two blasts and compared with assaying data. As described in Sect. 2.1, an average iron content has been obtained at intervals of $6 \mathrm{~m}$ for the blastholes measured. The value of the strength-grade factor section associated with the interval of each assay has been used. In case an interval includes two sections, the value of the longest portion of the section has been considered. The results of the analysis are plotted in Fig. 12b, where different shapes of markers are used
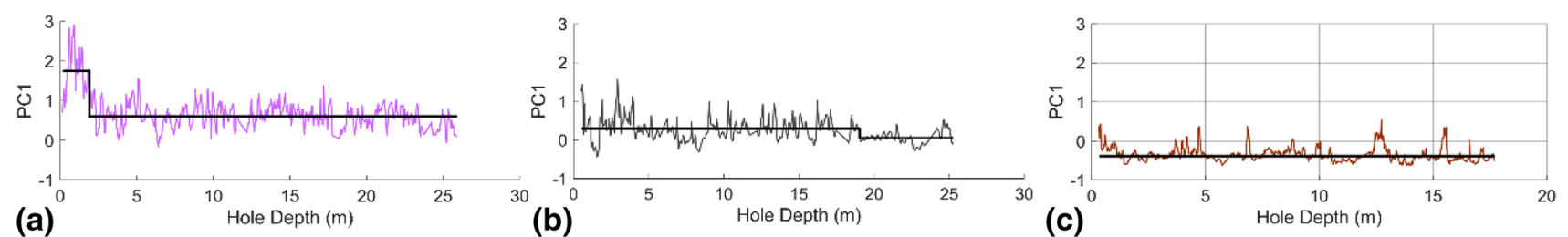

Fig. 11 Division of the strength-grade factor in zones based on large abrupt changes in the mean value of the signal for blastholes drilled in: a schisted sandstone; b limestone; $\mathbf{c}$ siderite

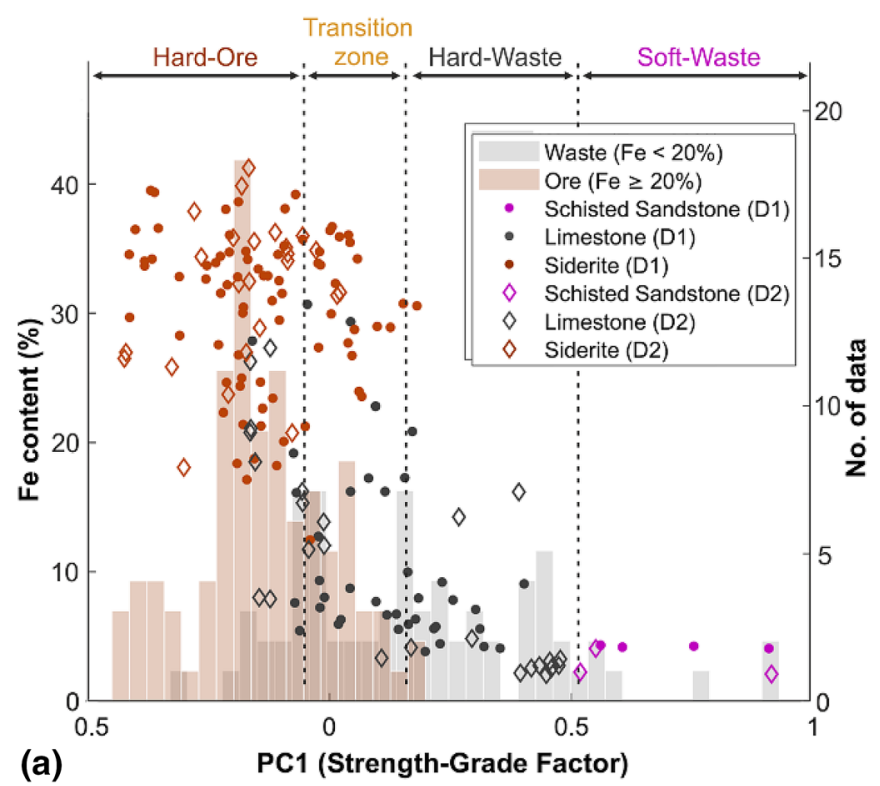

Fig. 12 a Correlation study between the MWD-calculated PC1 (strength-grade factor) and iron content associated with each hole. Strength-grade categories are shown. b Representation of the MWD-

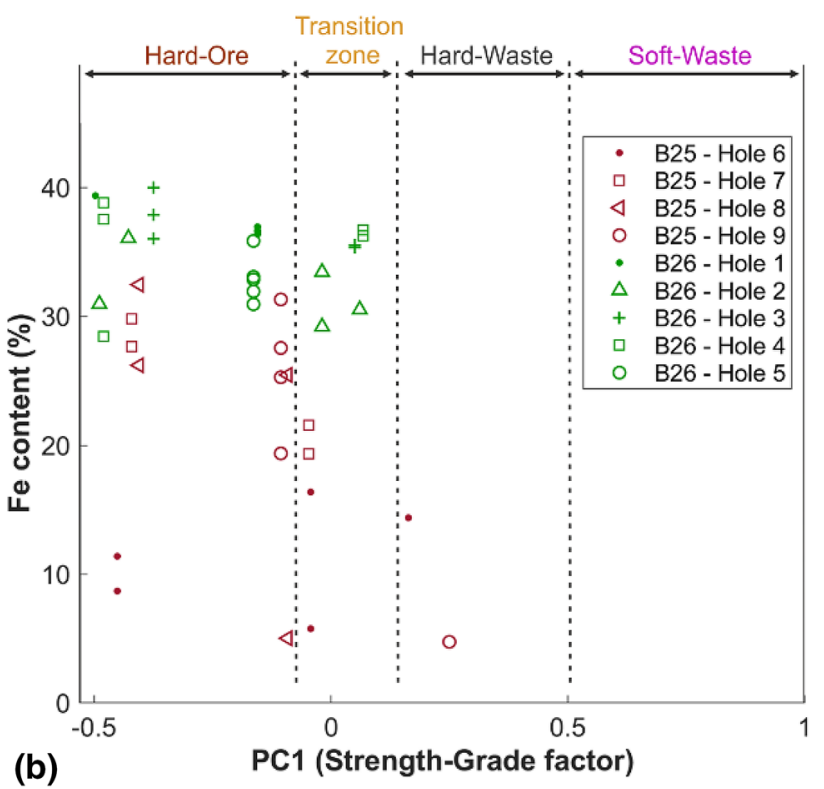

calculated PC1 (strength-grade factor) and the iron content for the validation data of blasts B25 and B26. 
for different holes and different colors for each blast. According to the graph, most of the samples were taken in siderite and are thus associated with hard-ore category. The model also identifies some measurements in the Transition zone associated with ore and waste material and two measurements in the hard-waste category. Only four of the markers linked to waste material are plotted in the hard-ore category, one of them with iron content very close to the ore threshold.

Figure 13 represents the application of the strength-grade factor (left column) and the ore/waste classification from the assays (right column) in four production blasts carried out in limestone (Blast B1, Fig. 13a), schisted sandstone (Blast B2, Fig. 13b), siderite (Blast B18, Fig. 13c) and in a combination of the three (Blast B16, Fig. 13d). In line to Fig. 13, the blasts used for the validation of the model are represented in Fig. 14a (B25) and b (B26); blastholes assayed are divided at intervals of $6 \mathrm{~m}$ by small black bold ovals. The blastholes, colored according to the strength-grade category defined from the MWD data, are represented together with the 3D reconstruction of the post-blast bench face. Sections of some blastholes in Figs. 14a (bottom right side) and 15b (bottom) are hidden by the remaining muck-pile, as from the UAV reconstruction, and they are represented behind a more transparent terrain.

The strength-grade factor accurately matches the lithologies represented and the ore/waste identification. In Fig. 13a (left graph), the left side is associated with limestone and identified as Hard-Waste. To the right side, some blastholes or long sections of blastholes are identified as Transition zone where a different lithology color indicates a possible siderite zone that intercepts the limestone. Among the six blastholes with transition zone, four of them are related to ore as from the assays (right graph). Figure $13 \mathrm{~b}$ and c (left graphs) show homogeneous lithologies for schisted sandstone (purple) and siderite (brown), respectively. The strength-grade factor identifies these two scenarios as SoftWaste in the former and hard-ore in the latter, matching with waste and ore material, respectively, as from the assays (right graphs).

Three lithologies can be distinguished in Fig. 13d, where the schisted sandstone area is associated to soft-waste category (first three blastholes, from left to right), the limestone area with hard-waste category (next two blastholes) and the siderite area with hard-ore and some transition zone categories (for the remaining ones). The results are in line with the ore/waste identification (right graph); the transition zone is related to ore. Blastholes 9 and 10 (from left to right) show a Hard-Waste section in the upper part, that may be related to a change in the rock properties, as can be appreciated by the darker color in this zone; however, the assays associate these holes to ore. The bottom part of blastholes 4 and 5 (from left to right) shows a change of the rock to hard-ore category.
According to the color of the floor, the ore limit dips towards the left, matching with the hard-ore identification.

Figure 14a shows the three lithologies. In the left graph, the top part of blastholes 1 and 2 (from left to right) is identified as Soft-Waste, corresponding to a schisted sandstone area. The area of limestone (greenish-gray color defined by the two white dashed lines) is associated to the Transition zone category, indicating possible different strengths than for limestone in the areas shown in Fig. 13a and d. The siderite area to the right side is related to hard-ore category. The ore/waste identification at intervals of $6 \mathrm{~m}$ length is represented for blastholes 6-9 (from left to right); this makes five sections for holes 6 and 9 and four for holes 7 and 8 (right graph). These intervals are plotted in Fig. 12b with dark red markers. Overall, the strength-grade factor identifies both lithologies and Fe grade; exceptions are blastholes 6, Sects. 4 and 5 (from top to bottom), and 8 , first section, defined as hard-ore and associated to waste material (see black ovals). However, for Sects. 4 and 5 in blasthole 6, the rock color in the $3 \mathrm{D}$ reconstruction is similar to the siderite and may indicate an area of similar strengths.

In Fig. 14b, the main area of the bench is siderite, being blastholes 1-5 (from left to right) identified as hard-ore and Transition zone (left graph). The chemical analysis of these blastholes, represented by green markers in Fig. 12b, associates them to ore for all sections; the right graph shows these results. To the right, there is a hole drilled in an area associated to limestone and a potential intrusion of schisted sandstone rock type. The model identifies them with SoftWaste and Hard-Waste categories (left graph).

The strength-grade factor has been applied to map the whole mine area where the data were collected (Table 2). The results are represented in Fig. 15. The model identifies areas of hard-ore and some transition zones in the center of the deposit (marked with two dark green dashed lines), indicating potential areas of ore material in this zone. To the left side of the graph, areas of soft-waste, hard-waste and transition zones appear, representing potential intrusions of limestone and schisted sandstone rock types in the deposit. The right side of the graph is barely measured, making it difficult to define the rock material. Blasts described in Figs. 13 and 14 are marked with white ovals. In general, the categories identified by the strength-grade factor are in line with the different lithologies observed in the 3D reconstructions.

\section{Drilling Rock Factor model}

Blasting operations results are mainly influenced by the geomechanical and geotechnical properties of the rock mass (rock strength and structural condition) and blast design parameters such as the explosive type, charge concentration, blast timing, drill pattern and drilling deviations (Ibarra et al. 

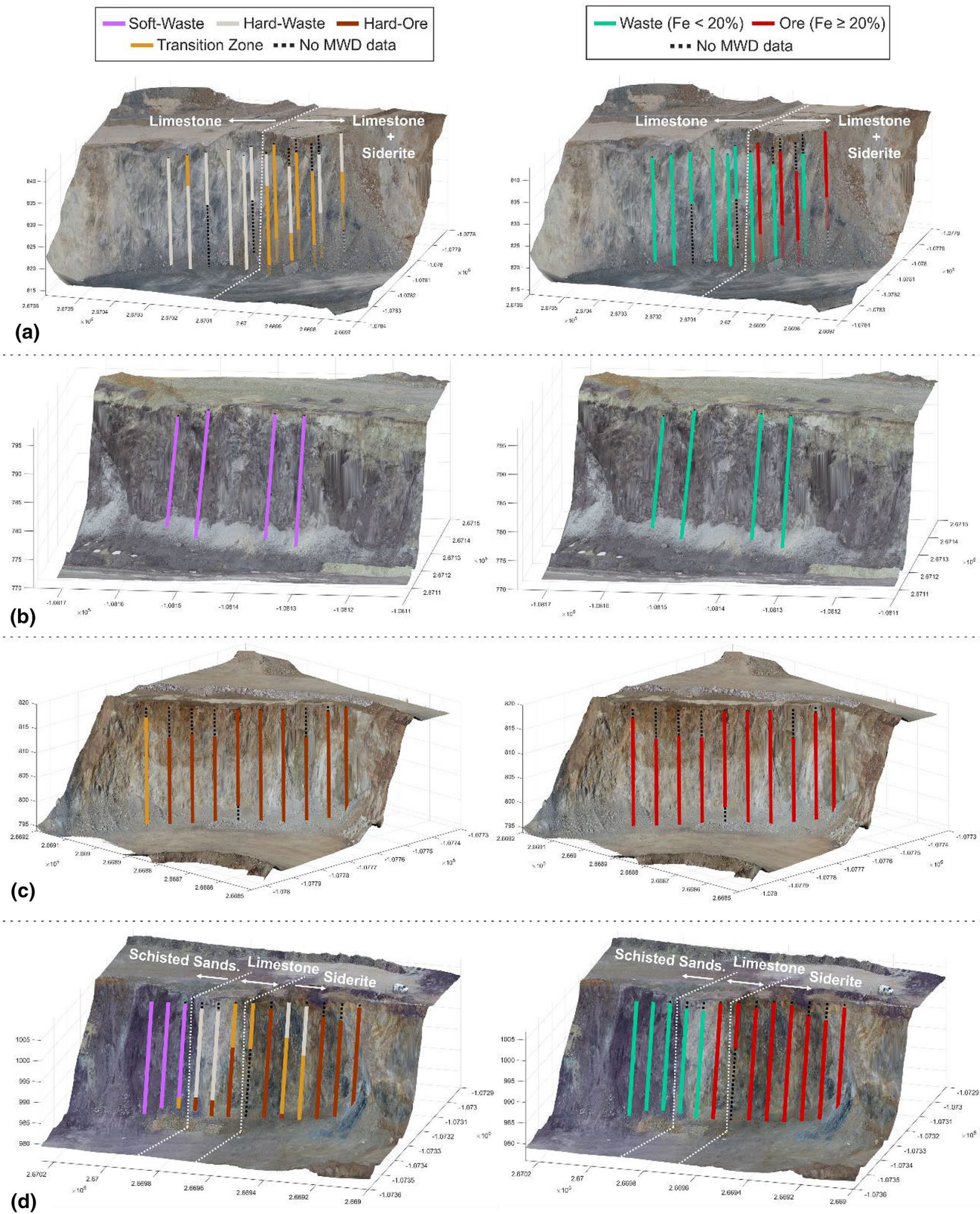

Fig. 13 Application of the strength-grade factor in production blasts (left column) and comparison to the ore/waste classification from the assays (right column): a blast B1 (limestone + intrusions of siderite);

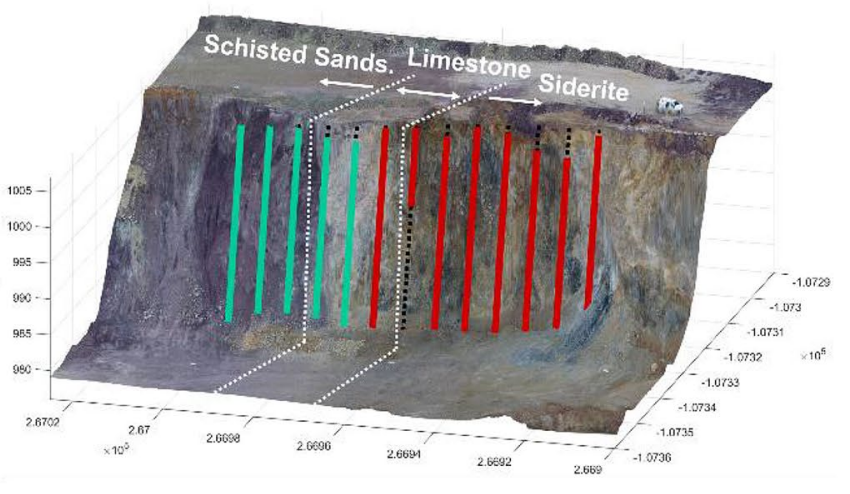

b blast B2 (schited sandstone); c blast B18 (siderite); d blast B16 (schisted sandstone + limestone + siderite) 

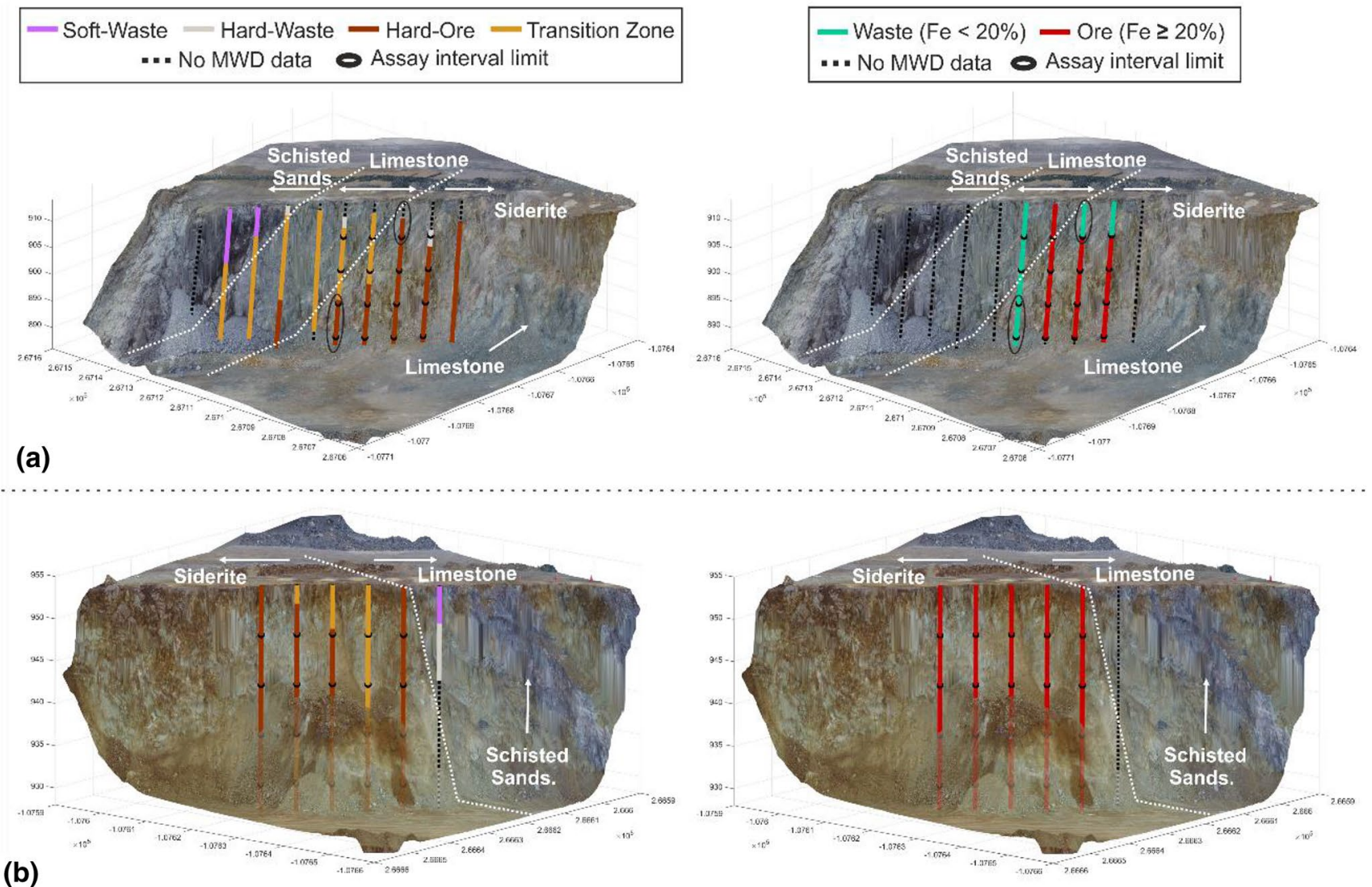

Fig. 14 Application of the strength-grade factor (left column) in blasts used for validation of the model and comparison to the ore/

umn): a blast B25 (schisted sandstone + limestone + siderite); b blast B26 (schisted sandstone + limestone + siderite)

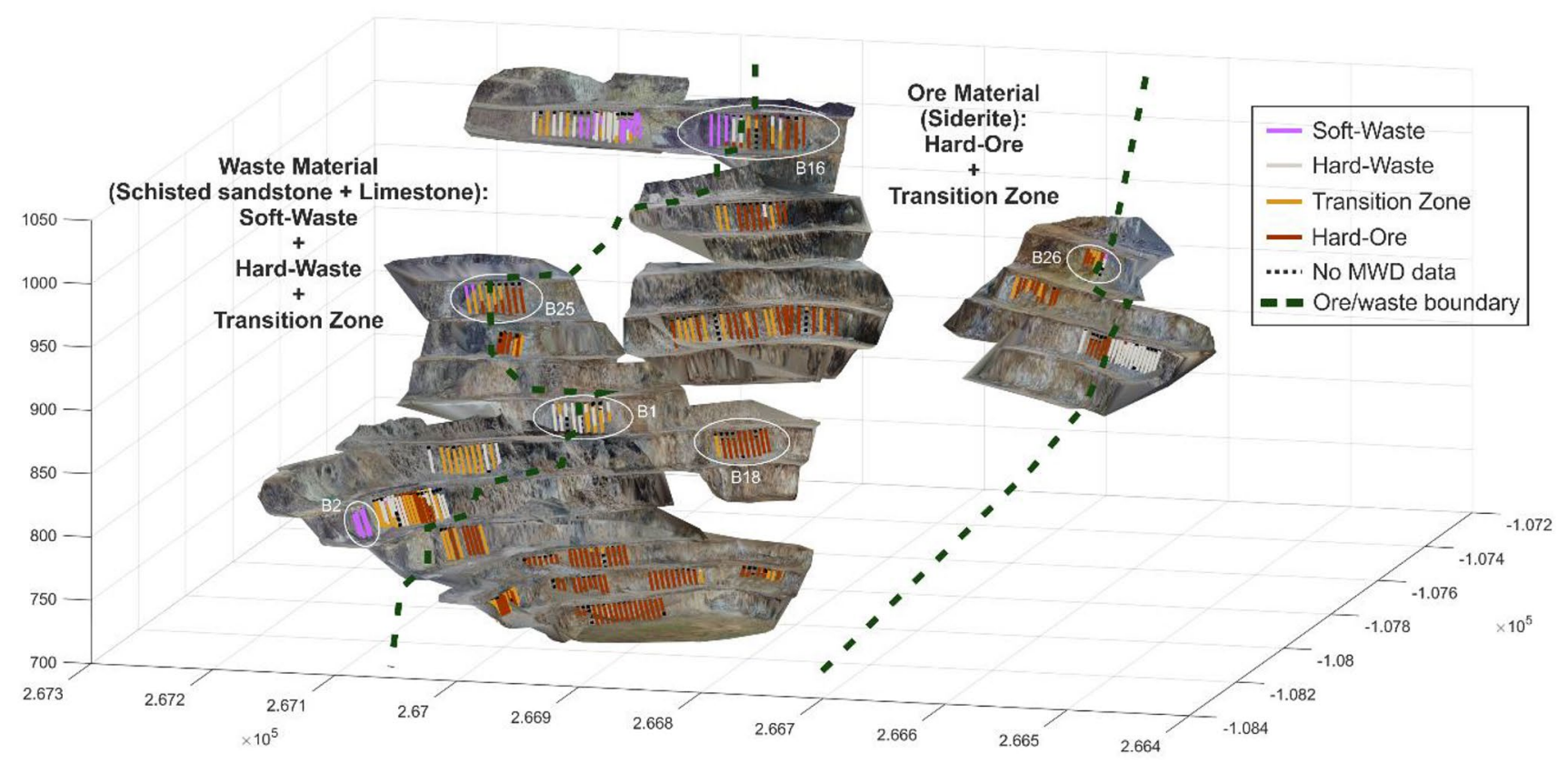

Fig. 15 Application of the strength-grade factor to the whole mine area where the data were collected 
1996; Oggeri and Ova 2004; Singh et al. 2003; Singh and Xavier 2005; Hustrulid 2010; Johnson 2010; Hu et al. 2014).

The structural block model has been combined with the strength-grade factor in an overall rock factor, exclusively obtained from drill monitoring data, to provide an assessment of the structural condition, strength properties and waste/ore identification of the rock blasted. For each strength-grade factor category, there are three structural classes, making twelve different rock factor categories. Figure 16 represents the application of the Rock Factor in the production blasts shown in Figs. 13 and 14. Blastholes are colored according to the Rock Factor category (see legend). As in Figs. 13 and 14, the color-scheme associated to the strength-grade factor categories identifies schisted sandstone, limestone, and siderite lithologies represented in the 3D reconstruction of the post-blast bench face. Sections of blastholes hidden by the remaining muck-pile (Fig. 16, graphs a and f) are represented behind a more transparent material.

In relation to the structural conditions and in line with results from blast B14 in Fig. 9, the first meters of the blastholes normally show a combination of fractured and heavily fractured zones, that may be related to broken or damaged rock from upper blasts or the backfill material used to flatten out the ground. The rock factor in Fig. 16a shows a massive area intersected by fractured or heavy fractured zones of at least $0.3 \mathrm{~m}$ length, according to the minimum length of each section. Potential connections between discontinuities of adjacent holes have been marked (black dashed closed contour), as a consequence of discontinuities dipping-out-the-face. Figure $16 \mathrm{~b}$ shows areas of heavily broken material in the first 5-7 m (top black closed contour) well defined by the model. The rock factor also identifies other two Fractured and Heavily Fractured zones in blastholes 2 and 3 (from left to right, see bottom black ovals) that can be associated to an area of a more intense fractured rock shown around blasthole 2, and a large discontinuity crossing blasthole 3 . The Rock Factor in Fig. 16c identifies zones of massive rock intersected by trends of fractured areas connecting adjacent holes (see black closed contour). These areas have been verified with blastholes records. A possible discontinuity connection between adjacent holes has been marked with a dashed black closed contour. Figure 16d shows an area of heavily broken material in the first 5-7 $\mathrm{m}$ for all the holes (top black closed contour), identified by the model as Fractured and Heavily Fractured categories, and two small Fractured and Heavily Fractured zones in the schisted sandstone and the limestone (lower black closed contour on the left) that are associated to areas of a more intensely fractured rock. The siderite side is more massive, with possible discontinuities across holes (dashed black closed contour). In Fig. 16e, the 3D reconstruction shows a very irregular face for the three lithologies, which may indicate areas of intense fractures and discontinuities (see black closed contour). These are identified by the rock factor as heavily fractured (for schited sandstone) and fractured (for limestone and siderite) categories. Finally, the 3D reconstruction of Fig. 16f shows a very homogenous face which is correlated with extensive massive zones along the holes.

\section{Conclusions}

Two rock description indexes are derived directly from MWD data: one to classify the structural condition of the rock, and the other to assess the strength properties and iron content of the rock. To use the drilling parameters, corrections are carried out to minimize external influences other than the rock mass. These comprise: (1) filtering unrealistic values, (2) removing systematic peaks due to the addition of a new rod, and (3) correction of the hole depth influence. The corrected MWD data have been combined using PCA.

The first index is a structural factor that classifies the rock mass in three classes (massive, fractured and heavily fractured) from the variability of the MWD parameters and a discontinuity factor determined using PCA. Video records of the inner wall of 256 blastholes have been used to calibrate the results. The structural factor has been validated with one blast with accurate results. A structural block model has been developed as an improvement of this factor to simplify the automatic recognition of structural rock trends.

The second index is a strength-grade factor, based on the combination of MWD parameters in PCA, that has been assessed from the analysis of the rock type description and UCS from geology reports, assays of drilling chips (ore/ waste identification) and 3D UAV reconstructions of the post-blast bench face. Data from 286 blastholes from 24 blasts have been used for this analysis. Waste rock areas associated with schisted sandstone and limestone are normally related to high strength-grade factor values. Schisted sandstone has a UCS $=30 \mathrm{MPa}$ and its recognition from the drilling response is clear. On the other hand, blasts carried out in areas of siderite, the ore rock, are associated with low strength-grade factor values. Although limestone and siderite have a similar UCS value around $125 \mathrm{MPa}$, the strength-grade factor normally can differentiate these two rock types; however, there are some situations where the drilling responds similar. The strength-grade factor ranks the rock into four categories: soft-waste, hard-waste, transition zone and hard-ore. The strength-grade factor has been validated for two blasts that were left out of the development of the model; it was compared to the iron content from assays at intervals of $6 \mathrm{~m}$ for nine holes. The results determine zones of soft and hard waste material (schisted sandstone and limestone, respectively) and hard ore material zones (siderite).

Finally, the structural block model has been combined with the strength-grade factor in an overall rock factor, 


\begin{tabular}{|l|l|l|c|}
\hline & Massive Zone & Fractured Zone & Heavily Fractured Zone \\
\hline Soft-Waste & & & \\
\hline Hard-Waste & & & \\
\hline Transition Zone & & & \\
\hline Hard-Ore & & & \\
\hline
\end{tabular}

(a)
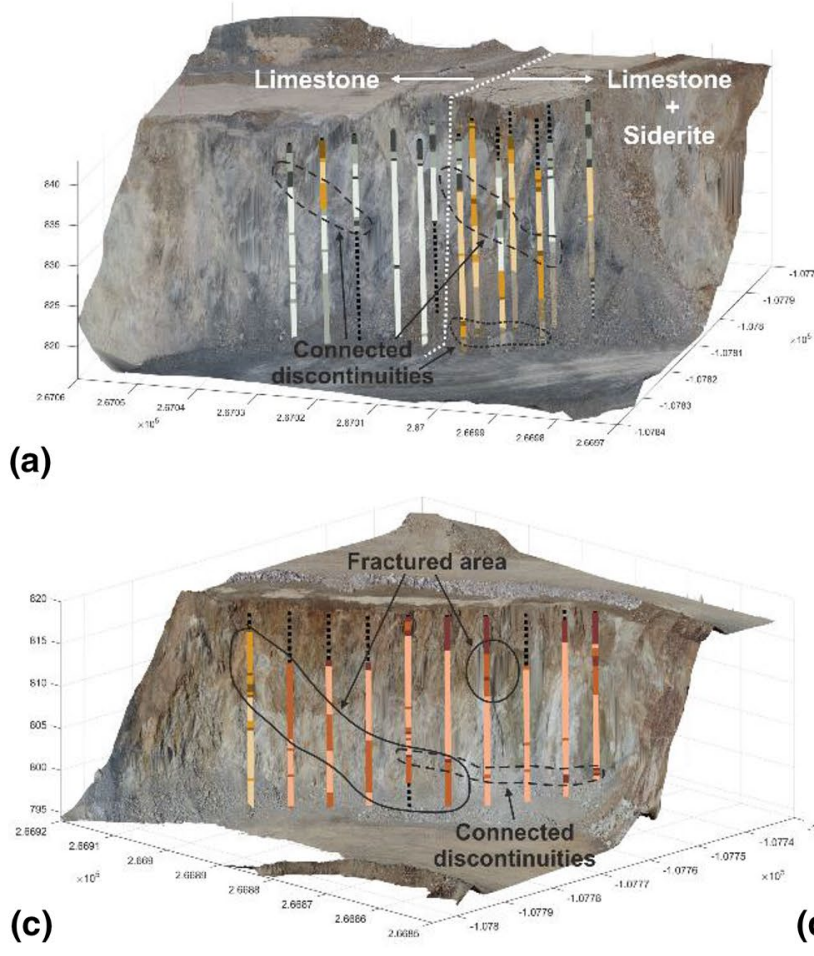

(c)

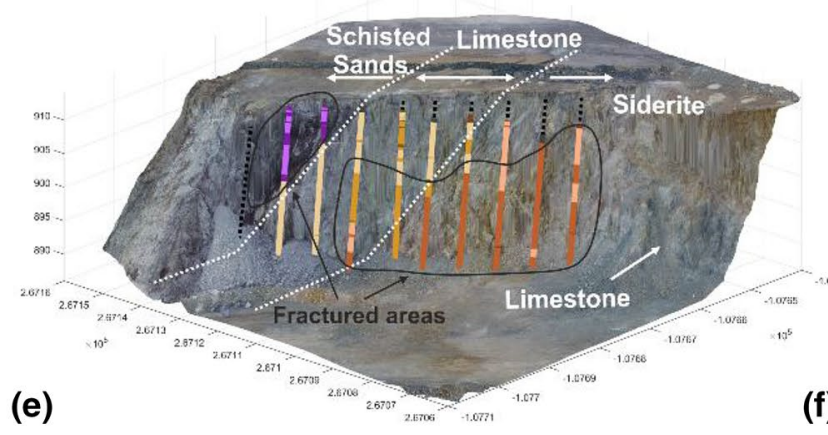

Fig. 16 Application of the rock factor model in production blasts; a blast B1 (limestone + intrusions of siderite); $\mathbf{b}$ blast B2 (schited sandstone); c blast B18 (siderite); d blast B16 (schisted sandstone + lime-

exclusively obtained from drill monitoring data, to assess the structural condition, strength properties and waste/ore identification of the rock. Assessments for different conditions would require a re-calibration of the model for the new site and drill rigs, following the methodology described.

A detailed rock mass characterization per hole in an overall Rock Factor exclusively obtained from MWD data, provides an early information of the rock to be mined, both in terms of strength and jointing, and in terms of ore grade. This factor allows improving blasts design, hence better

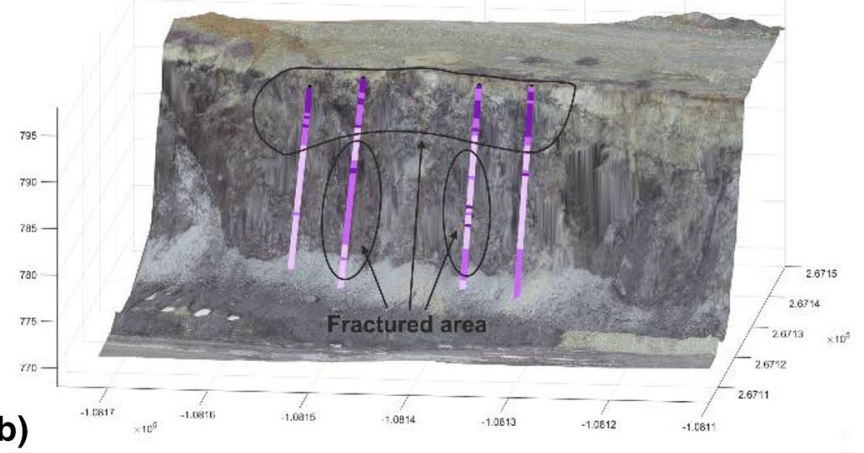

(b)

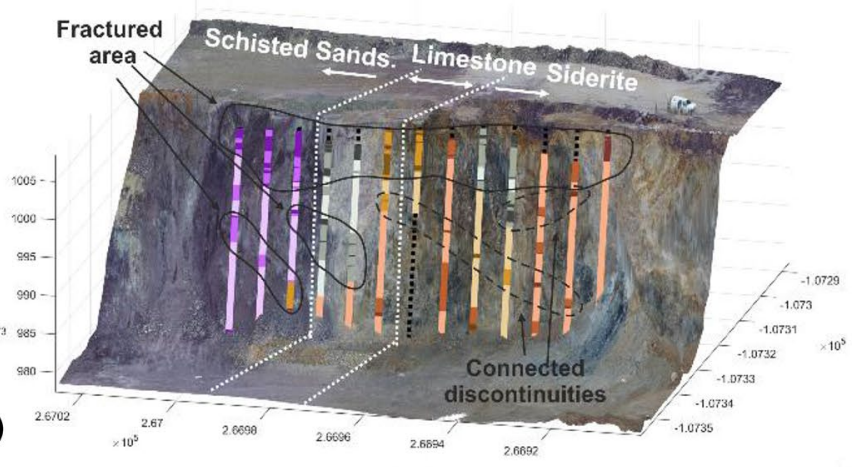

(f)

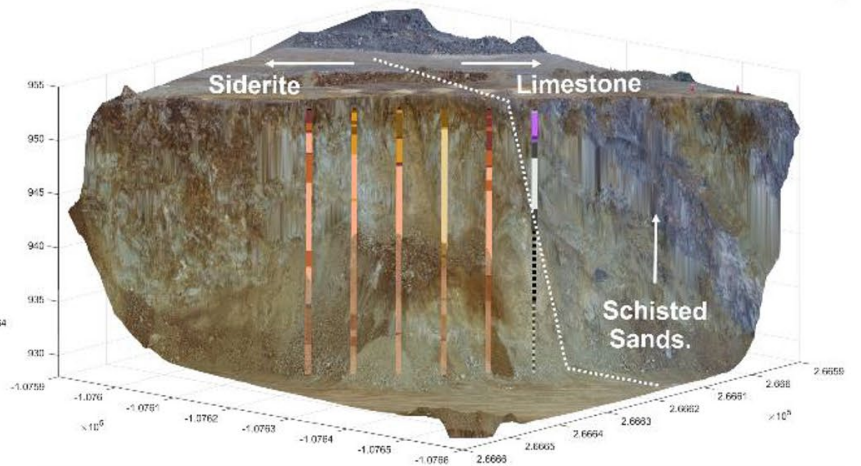

stone + siderite); e blast B25 used for validation of the model (schisted sandstone + limestone + siderite); f blast B26 used for validation of the model (schisted sandstone + limestone + siderite)

controlling blast results (e.g. rock fragmentation and wall stability), by adapting blast design parameters to the rock condition. In addition, the potential ore/waste identification from MWD data may help to an early and fast ore/waste rock classification, helping to prevent ore waste and dilution from blasting. The amount of assaying required may also be reduced resulting in cost savings.

Acknowledgements This work has been conducted within project "SLIM" funded by the European Union's Horizon 2020 research and 
innovation program under grant agreement no. 730294. The authors would like to acknowledge VA Erzberg $\mathrm{GmbH}$ for their valuable input into the project.

Open Access This article is licensed under a Creative Commons Attribution 4.0 International License, which permits use, sharing, adaptation, distribution and reproduction in any medium or format, as long as you give appropriate credit to the original author(s) and the source, provide a link to the Creative Commons licence, and indicate if changes were made. The images or other third party material in this article are included in the article's Creative Commons licence, unless indicated otherwise in a credit line to the material. If material is not included in the article's Creative Commons licence and your intended use is not permitted by statutory regulation or exceeds the permitted use, you will need to obtain permission directly from the copyright holder. To view a copy of this licence, visit http://creativecommons.org/licenses/by/4.0/.

\section{References}

AMV (2019) www.amv.as. Accessed 2019

Aydan Ö, Ulusay R, Tokashiki N (2014) A new rock mass quality rating system: rock mass quality rating (RMQR) and its application to the estimation of geomechanical characteristics of rock masses. Rock Mech Rock Eng 47:1255-1276

Barton N, Lien R, Lunde J (1974) Engineering classification of rock masses for the design of tunnel support. Rock Mech Rock Eng 6(4):189-236

Bieniawski ZT (1995) Classification of rock masses for engineering: the RMR system and future trends. In: Rock testing and site characterization. Pergamon Press, 3:553-573

Bever Control (2020) www.bevercontrol.com Accessed 2020

Cunningham CVB (1987) Fragmentation estimations and the Kuz-Ram model-four years on. In: Proceedings of 2nd International Symposium on RockFragmentation by Blasting, Keystone, Colorado, USA, August, 461:475-487

Cunningham CVB (2005) The Kuz-Ram fragmentation model-20 years on. In: Brighton conference proceedings 201-210. European Federation of Explosives Engineers, England, 201-210

Deere DU, Miller RP (1966) Engineering classification and index properties for intact rock. Illinois University at Urbana, Department of Civil Engineering

Epiroc (2020) www.epiroc.com. Accessed 2020

Ghosh R (2017) Assessment of rock mass quality and its effects on charge ability using drill monitoring technique. Doctoral dissertation, Luleå Tekniska Universitet.

Ghosh R, Gustafson A, Schunnesson H (2018) Development of a geomechanical model for chargeability assessment of borehole using drill monitoring technique. Int J Rock Mech Min Sci 109:9-18

Hatherly P, Leung R, Scheding S, Robinson D (2015) Drill monitoring results reveal geological conditions in blasthole drilling. Int $\mathrm{J}$ Rock Mech Min Sci 78:144-154

Hjelme JG (2010) Drill parameter analysis in the Loren tunnel, M.Sc. thesis in Geosciences, University of Oslo, Department of Geosciences

Hoek E (1994) Strengths of rock and rock masses. ISRM News J 2(2):4-16

Hu Y, Lu W, Chen M, Yan P, Yang J (2014) Comparison of blastinduced damage between presplit and smooth blasting of high rock slope. Rock Mech Rock Eng 47(1):1307-1320

Hustrulid W (2010) Some comments regarding development drifting practices with special emphasis on caving applications. Min Technol 119(3):113-131
Ibarra JA, Maerz NH, Franklin JA (1996) Overbreak and underbreak in underground openings part 2: causes and implications. Geotech Geol Eng 14(4):325-340

Johnson JC (2010). The hustrulid bar - a dynamic strength test and its application to the cautious blasting of rock. Dissertation submitted to the faculty of in partial fulfillment of the requirements for the degree of Doctor of Philosophy, Department of Mining Engineering, The University of Utah, USA.

Kahraman S, Rostami J, Naeimipour A (2016) Review of ground characterization by using instrumented drills for underground mining and construction. Rock Mech Rock Eng 49(2):585-602

Killick R, Fearnhead P, Eckley IA (2012) Optimal detection of changepoints with a linear computational cost. J Am Stat Assoc 107(500):1590-1598

Kuznetsov VM (1973) The mean diameter of the fragments formed by blasting rock. Sov Min 9(2):144-148

Lavielle M (1999) Detection of multiple changes in a sequence of dependent variables. Digit Signal Process 83(1):79-102

Lavielle M (2005) Using penalized contrasts for the change-point problem. Digit Signal Process 85:1501-1510

Leung R, Scheding S (2015) Automated coal seam detection using a modulated specific energy measure in a monitor-while-drilling context. Int J Rock Mech Min Sci 75:196-209

Lilly PA (1986) An empirical method of assessing rock mass blastability. Large open pit mining conference, Newman, pp 89-93

Lilly PA (1992) The use of the blastability index in the design of blasts for open pit mines. In: Proceedings of Western Australian conference on mining geomechanics, Kalgoorlie, West Australia, pp 8-9

Liu H, Karen YK (2001) Analysis and interpretation of monitored rotary blasthole drill data. Int J Min Reclam Env 15:177-203

Matlab (2017) The MathWorks Inc, Natick

Navarro J (2019) The use of measure while drilling for rock mass characterization and damage assessment in blasting. Ph.D. thesis, Dept. of. Geological and Mining Engineering. Universidad Politécnica de Madrid

Navarro J, Sanchidrián JA, Segarra P, Castedo R, Costamagna E, López LM (2018) Detection of potential zones in tunnel blasting from MWD data. Tunn Undergr Space Technol 82:504-516

Navarro J, Schunnesson H, Ghosh R, Segarra P, Johansson D, Sanchidrián JA (2019) Application of drill-monitoring for chargeability assessment in sublevel caving. Int J Rock Mech Min Sci 119:180-192

Oggeri C, Ova G (2004) Quality on tunneling: ITA-AITES Working Group 16 final report. Tunn Undergr Space Technol 19:239-272

Palmström A, Sharma VI, Saxena K (2001) In situ characterization of rocks. BALKEMA Publ, Leiden, pp 1-40

Pearse G (1985) Hydraulic rock drills. Mining Magazine, March

Peck J (1989) Performance monitoring of rotary blast hole drills. Doctoral Thesis, McGill University, Montreal, Canada

Peng SS, Tang D, Sasaoka T, Luo Y, Finfinger G, Wilson G (2005) A method for quantitative void/fracture detection and estimation of rock strength for underground mine roof. In: 24th international conference on ground control in mining,02-04 August, West Virginina (EEUU), pp 187-195

PIX4D (2020) www.pix4d.com Accessed 2020

Sanchidrián JA, Ouchterlony F (2017) A distribution-free description of fragmentation by blasting based on dimensional analysis. Rock Mech Rock Eng 50(4):781-806

Sandvik (2020) www.sandvik.com. Accessed 2018

Schunnesson H (1997) Drill process monitoring in percussive drilling for location of structural features, lithological boundaries and rock properties, and for drill productivity evaluation. Ph.D. thesis, Dept. of Environmental Planning and Design Division of Applied Geology, Luleå University of technology, Luleå

Schunnesson H (1998) Rock characterization using percussive drilling. Int J Rock Mech Min Sci 35:711-725 
Schunnesson H, Elsrud R, Rai P (2011) Drill monitoring for ground characterization in tunneling operations. In: Proceedings of 20th internationalsymposium on mine planning and equipment selection (MPES2011), 12-14 October 2011, National Center on Complex Procession of Mineral RawMaterials of the Republic of Kazakhstan, Almaty, Kazakhstan

Schunnesson H, Poulopoulos V, Bastis K, Pettersen N, Shetty A (2012) Application of computerized drill jumbos at the Chenani-Nashri tunnelling site in Jammu-Kashmir, India. In: Proceedings 21st International Symposium on Mine Planning and Equipment Selection, 28-30 November, New Delhi, India, pp 729-751

Scoble MJ, Peck J, Hendricks C (1989) Correlation between rotary drill performance parameters and borehole geophysical logging. J Min Sci Technol 8(3):301-312

Singh SP, Xavier P (2005) Causes, impact and control of overbreak in underground excavations. Tunn Undergr Space Technol 20:63-71

Singh PK, Roy SK, Sinha A (2003) A new blast damage index for the safety of underground coal mine openings. J Min Sci Technol 112(2):97-104

Tang X (2006) Development of real time roof geology detection system using drilling parameters during roof bolting operation. Ph.D.
Thesis, Department of Mining Engineering, University of West Virginia

Teale R (1965) The concept of specific energy in rock drilling. Int J Rock Mech Min Sci 2:57-73

van Eldert J, Schunnesson H, Johansson D, Saiang D (2020) Application of measurement while drilling technology to predict rock mass quality and rock support for tunneling. Rock Mech Rock Eng 53:1349-1358

Wold S, Esbensen K, Geladi P (1987) Principal component analysis. Chemom Intell Lab Syst 2:37-52

Zhao K, Gu S, Yan Y, Li Q, Xiao W, Liu G (2018) Rock mechanics characteristics test and optimization of high-efficiency mining in dajishan tungsten mine. Geofluids 2018:8036540

Publisher's Note Springer Nature remains neutral with regard to jurisdictional claims in published maps and institutional affiliations. 